\title{
Retinotopic Organization of the Developing Retinotectal Projection in the Zebrafish Embryo
}

\author{
Claudia A. O. Stuermer \\ Friedrich-Miescher-Laboratorium der Max-Planck-Gesellschaft, D-7400 Tübingen, Federal Republic of Germany
}

\begin{abstract}
Developing retinal axons in the zebrafish embryo were stained with HRP or with the fluorescent dyes dil and diO to study the formation of the retinotectal projection. Retinal axons leave the eye at 34-36 hr postfertilization (PF), invade the tectum at 46-48 hr PF, and innervate the tectal neuropil at 70-72 hr PF. Dorsal and ventral axons occupy separate aspects of the optic nerve and tract and pass into their retinotopically appropriate ventral and dorsal hemitectum, respectively. Nasal and temporal axons are segregated in the nerve, mixed in the tract, and are coextensive over the rostral half of tectum until 56 hr PF. They then segregate again, due to the progression of nasal axons into the open caudal tectum. Thus, at 70-72 hr PF, dorsal and ventral as well as temporal and nasal axons occupy their retinotopically appropriate tectal quadrants. After ablation of the temporal retina prior to the time of axonal outgrowth, the nasal axons bypass the vacant rostral tectum to terminate in the caudal tectal half. Temporal axons in the absence of nasal axons remain restricted to their appropriate rostral tectai half, suggesting that nasal and temporal axons possess a preference for their retinotopically appropriate tectal domains.

Measurements of individual terminal arbors and the tectal areas in embryos and in adult zebrafish showed that individual arbors are large with respect to the embryonic tectum but are about 14-15 times smaller than in the adult. However, the proportion of tectum covered by embryonic arbors is about 7 times larger than in the adult, suggesting that a higher precision of the adult projection is achieved as a result of a greater enlargement of the tectum than of the arbors.
\end{abstract}

In fish, as in other vertebrates, the axons of the retinal ganglion cells connect with the contralateral tectum in an orderly manner and create a topographic map of the visual world. In an attempt to understand how such maps are formed, most studies have concentrated on the regeneration of the retinotectal projection rather than on its embryonic development (Attardi and Sperry, 1963; Jacobson and Gaze, 1965; reviewed by Gaze, 1970; Meyer

\footnotetext{
Received Nov. 27, 1987; revised Mar. 11, 1988; accepted Mar. 13, 1988.

I wish to thank Dr. J. Raper for helpful corrections to the manuscript and Dr. C. Holt for her advice on the HRP staining of axons in the early embryos. J. Vielmetter and $\mathbf{S}$. Bolz cared for the zebrafish breeding colony. The experiments. camera lucida tracings, and measurements were performed with the excellent technical assistance of A. Habring and B. Krauss. I thank R. Groemke-Lutz for her skillful photographic reproductions.

Correspondence should be addressed to Claudia A. O. Stuermer, FriedrichMiescher-LaboratoriumderMax-Planck-Gesellschaft, Spemannstr. 37-39, D-7400 Tübingen, FRG

Copyright (C) 1988 Society for Neuroscience $0270-6474 / 88 / 124513-18 \$ 02.00 / 0$
}

and Sperry, 1976; Cook and Horder, 1977). Although still widely reproduced (Kandel and Schwartz, 1985; Purves and Lichtman, 1985), Attardi and Sperry's view that regenerating axons follow normal routes, grow directly toward their target sites, and reestablish a topographic projection shortly after their arrival in the tectum (Attardi and Sperry, 1963) has had to be modified. More recent findings have shown that retinal axons do not course directly towards their target in either the normal adult (Stuermer and Easter, 1984a) or in the regenerate (Cook, 1983; Stuermer and Easter, 1984b). Instead, axonal pathways in tectum in the normal adult are the complex result of continuous terminal arbor rearrangement or "shifting" during the ongoing growth of retina and tectum (Raymond and Easter, 1983; Easter and Stuermer, 1984; Stuermer and Easter, 1984b). Regenerating axons which regrow to tectum after optic nerve section neither restore this growth-related axonal order (Stuermer, 1986) nor grow straight to their target sites in tectum (Stuermer, 1986, $1988 \mathrm{a}, \mathrm{b})$. Instead, they course in aberrant routes and form a map that is initially diffuse (Meyer et al., 1985; Rankin and Cook, 1986; Stuermer, 1988a, b). Only through course corrections and transient extensions of branches over ectopic tectal regions do regenerating axons gain access to their target sites (Fujisawa et al., 1982; Stuermer, 1988b). Various theories have been proposed to account for the reformation of the retinotopic map (Sperry, 1963; Willshaw and von der Malsburg, 1976; Cook and Horder, 1977; Fraser, 1980; Rankin and Cook, 1986); however, path- and homcfinding of regenerating axons appears to be best explained by a mechanism that involves axonal guidance by positional information on the tectum (Sperry, 1963; Bonhoeffer and Gierer, 1984; Gierer, 1987; Stuermer, 1988a-c; Stuermer and Vielmetter, 1987a; Walter et al., 1987a, b) and an activity-mediated sharpening of the initially unrefined projection (Schmidt and Edwards, 1983; Cook and Rankin, 1986).

In sum, the maintenance of the retinotopic map in the adult and its reformation in the regenerate appears to be better understood than its embryonic development. Therefore, it is most important to unravel how embryonic axons course towards and through tectum and to determine whether the embryonic tectal projection is diffuse as in regenerates or retinotopic and precise.

Some aspects of the embryonic development of the retinotectal projection in lower vertebrates have been revealed in amphibians and chick (Rager and von Oeynhausen, 1979; Holt and Harris, 1983; Harris, 1984; Thanos and Bonhoeffer, 1987). In the chick, axons grow in an orderly spatial and temporal sequence to tectum. This has been proposed to be sufficient for the creation of an orderly arrangement of axon terminals in tectum (Rager and von Oeynhausen, 1979). In Xenopus, Gaze and colleagues (1974) suggested that the early projection lacks 
its proper organization and is shaped to a retinotopic map by elimination of aberrant terminals. However, recent experiments have shown that the initial pathway and projection is topographically organized in the dorsal/ventral as well as in the rostrocaudal axis (Holt and Harris, 1983). In contrast to this report, a study by O'Rourke and Fraser (1986) proposed that the projection of the nasal and temporal axons along the rostrocaudal axis of tectum overlaps and that nasal and temporal axons only segregate after a delay of several days to occupy retinotopic positions.

The present study investigates the development of the retinotectal projection in embryonic fish. Results show that the retinotopic map is both retinotopic and relatively precise as soon as the axons have occupied the tectal neuropil. Zebrafish were chosen as experimental animals since under proper conditions they breed daily throughout the year and embryos develop rapidly in a reliable time sequence. The eggs are translucent, which allows proper developmental staging.

The following experiments were performed: First, labeling axons with HRP or the fluorescent dyes diI and diO established the sequence of axonal growth from the eye to the tectum. Second, local dye applications to defined sites in retina demonstrated the retinotopic order of axons in the nerve, tract, and tectum. Third, it is shown that axons from one-half of retina in the absence of axons from the other retinal half settle at their retinotopic tectal territories and do not invade inappropriate tectal domains. Fourth, measurements of terminal arbors and tecta revealed that the tectal area covered by the arbors is 7 times smaller in adult zebrafish than in the embryo.

Some of these results have appeared in abstract form (Stuermer and Vielmetter, 1987b).

\section{Materials and Methods}

Embryos of the zebrafish, Brachydanio rerio, were obtained from a laboratory colony and raised at $28^{\circ} \mathrm{C}$. Eggs were collected and staged within 1-2 hr after spontaneous spawning. Zebrafish hatch at about 48 hr and reach adulthood by 3-4 months. For experimental manipulations on embryos prior to hatching, embryos were freed from their egg cases with pointed metal needles. Embryos were placed on moist tissue and anesthetized with $0.007 \%$ MS 222. They were kept in $10 \%$ Hank's solution after surgery, where they develop normally.

Labeling of axons with HRP. HRP (Miles) was dissolved in $0.2 \%$ lysolecithin and redried onto the tip of a glass needle $(50 \mu \mathrm{m}$ tip diameter). The eyes were opened frontally with sharpened metal needles. To label all ganglion cell axons, large crystals of HRP about $100 \mu \mathrm{m}$ diameter were introduced into the eye cup and allowed to dissolve from the needle. To label a selected group of axons, a needle with an HRP crystal $<30 \mu \mathrm{m}$ diameter was poked into the dorsal, ventral, nasal, or temporal retina.

After $30 \mathrm{~min}$, the embryos were fixed in 4\% glutaraldehyde in PBS ( $\mathrm{pH} \mathrm{7.4)} \mathrm{for} 15 \mathrm{~min}$ and washed in PBS. For sectioning, the fixed embryos were embedded in albumin-gelatin (30\% albumin, $0.47 \%$ gelatin, $0.91 \% \mathrm{NaCl}$ ) and cut serially in the transverse plane at $30 \mu \mathrm{m}$ on a Vibratome. Sections were mounted on gelatinized slides, incubated for $15 \mathrm{~min}$ in $0.05 \%$ diaminobenzidine (DAB) in PDS with $1 \mathrm{ml} 30 \%$ $\mathrm{H}_{2} \mathrm{O}_{2} / 100 \mathrm{ml}$ solution, rinsed in PBS, dehydrated, and embedded in Permount. To prepare whole mounts of the brain, the eyes and the skin overlying the brain were removed. The brains were reacted in DAB (see above) for $10 \mathrm{~min}$ and, after rinses in PBS, were postfixed for $1 \mathrm{hr}$. They were placed onto gelatinized slides, weighed down with coverslips (for $2 \mathrm{hr}$ ), dehydrated, and embedded in Permount. HRP staining of retinal axons in the adult zebrafish were performed according to a protocol described in detail elsewhere (Stuermer, 1986, 1988a).

Labeled axons were viewed and photographed under a Zeiss Axiophot equipped with Nomarski optics. Camera lucida drawings were made on a Zeiss photomicroscope with $100 \times$ oil-immersion lenses and Nomarski optics.

Labeling of axons with fluorescent dyes. The fluorescent dyes of the carbocyanine group, 1, $1^{\prime}$-dioctadecyl-3,3,3',3'-tetramethylindocarbocyanine (diI) and 3,3'-dioctatecyloxacarbocyanine perchlorate (diO) were obtained from Molecular Probes (Junction City, OR). They are water insoluble but are taken up by cells and their processes when the dye is in physical contact with the cells (Honig and Hume, 1986). Small crystals (40-60 $\mu \mathrm{m}$ diameter) were taken up with glass needles and introduced in the desired position in the retinas of embryos between 30 and $60 \mathrm{hr}$ postfertilization (PF). Embryos were allowed to survive and continued to develop normally. At defined stages (between $48-80 \mathrm{hr}$ PF), embryos were fixed in 4\% paraformaldehyde in PBS for $15-30 \mathrm{~min}$. After removal of the eyes and the skin over the brain, the heads of the embryos were placed on their slides in a drop of Voltaleff oil $(10 \mathrm{Si})$ and protected by a coverslip. Preparations were observed and photographed with a Zeiss Axiophot using standard rhodamine (Zeiss 487715) and fluorescein (FITC Zeiss 487709) filter sets. Excited and viewed with their appropriate filter sets, respectively, diI-labeled cells and axons fluoresce red and diOlabeled profiles green (Honig and Hume, 1986). Dil-labeled processes appear yellow under the FITC filter set. This made it possible to observe diI- and diO-labeled axons simultaneously within one preparation. Under UV illumination, diO staining faded from axons within 10-15 min, whereas dil staining persisted for an hour or more.

Partial retinal ablations. To ablate half of the retina, either the nasal, temporal, dorsal, or ventral half of the eye was removed with sharpened metal needles in embryos $28-36 \mathrm{hr}$ old. In most eyes, the ablated half regenerated within approximately $12-20 \mathrm{hr}$ after surgery. Therefore, the operations were repeated at $48 \mathrm{hr}$. These injuries gave eyes of different sizes ranging from complete eye loss, over small eye fragments, half eyes to eyes with normal appearance. Only fish with eyes approximately half the size of normal eyes were used to label the retinal axons.

Approximately 300 embryos were used, of which, depending on the experiment, $20-30 \%$ were adequately stained to provide useful information. The number of "successful" cases is given in Results (indicated by $N$ ), along with the description of the experimental groups. In experiments in which only one tracer was applied to the retina, only those cases in which the axons were adequately stained and the brains well preserved were considered successful; in experiments in which the 2 fluorescent tracers were used simultaneously, only those fish exhibiting red and green axons were evaluated. These comprised approximately $40 \%$ of the total number of fish exhibiting labeled axons.

\section{Results}

All embryos were staged within the first 1-2 hr PF. The progress of retinal axonal growth will be described with respect to the embryos' age in hours (hr PF).

\section{Path of embryonic retinal axons into tectum}

To learn the sequence in which the embryonic retinal axons grow from the eye to tectum, HRP was applied to the eyes of fish at defined ages: between 30 and $58 \mathrm{hr}$, and at 70, 72, 74, $80 \mathrm{hr}, 4 \mathrm{~d}$, and $8 \mathrm{~d} \mathrm{PF}$. The HRP-labeled axons were visualized $30 \mathrm{~min}$ after HRP application in DAB-reacted transverse sections (fish between 30 and $48 \mathrm{hr} \mathrm{PF}, N=39$ ) and in DABreacted whole mounts of the brains ( $40 \mathrm{hr} \mathrm{PF}$ and subsequent stages, $N=54$ ).

The first axons-not more than 1-6 individuals-leave the eye through the ventral fissure and appear in the optic stalk between 34 and $35 \mathrm{hr}$ PF. These first axons carry simple lanceolate growth cones $<5 \mu \mathrm{m}$ long, which occasionally exhibit long forward directed filopodia. The first axons travel either as individuals (Fig. 1) or in close association with one another in a mediolateral direction. They bend dorsally at the contralateral diencephalic wall and run relatively straight towards the tectum. When they have passed the level of the future chiasm, a large number of axons enter the stalk as a front, and they are followed by additional axons in time. Throughout their path toward tectum, the first axons are 50-80 $\mu \mathrm{m}$ ahead of the other axons (Fig. 2 ), and they are either unbranched, or, like the one shown in Figure 3, they carry numerous short sprouts. The first axons 


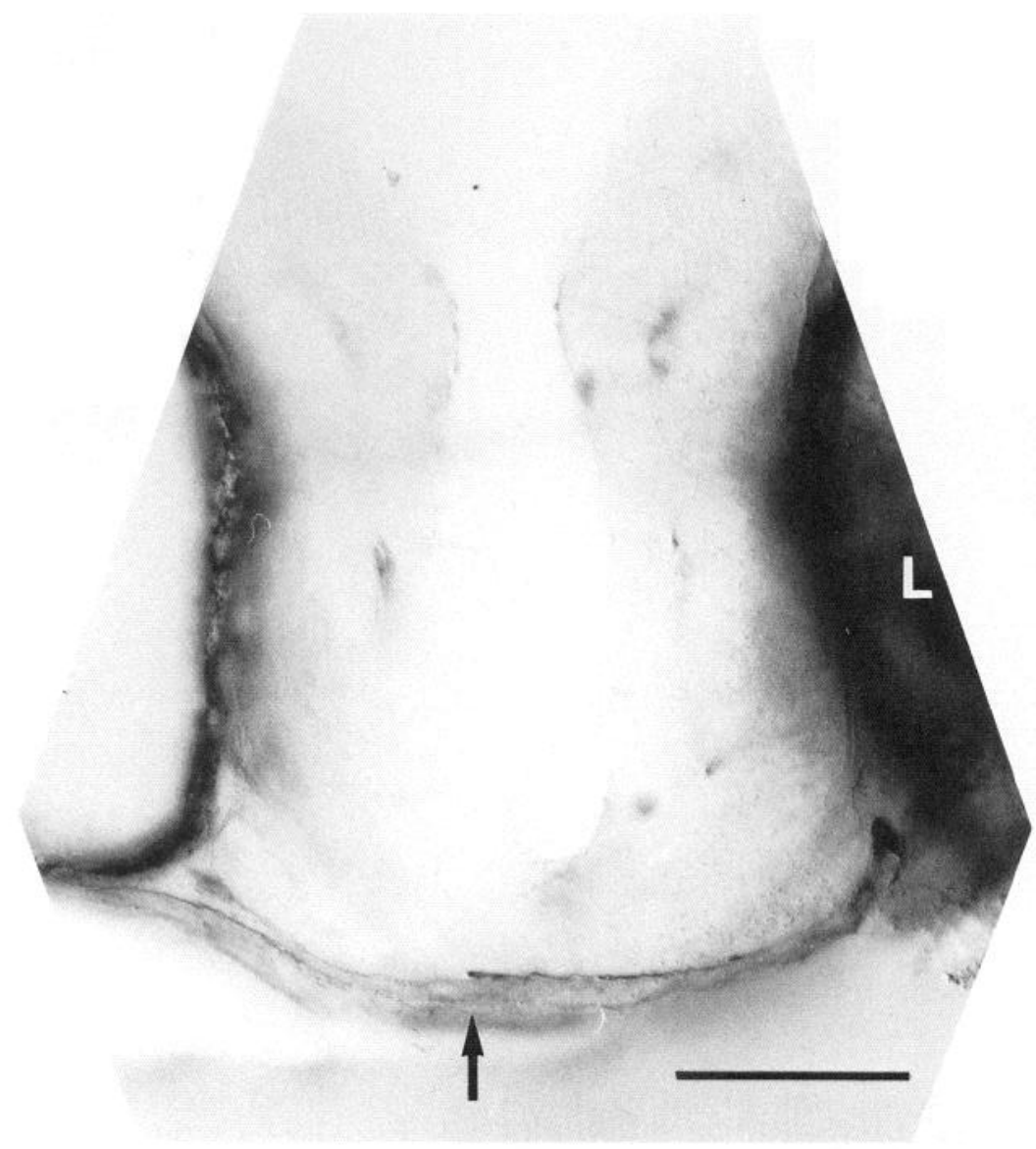

Figure 1. DAB-reacted transverse section through the eyes and brain of an embryo at $35 \mathrm{hr} \mathrm{PF}$, showing the first HRP-labeled retinal axons (arrow) in the optic nerve, which originate from the left eye $(L)$. Scale bar, $50 \mu \mathrm{m}$.



Figure 2. Lateral view of a whole mount of a brain at $45 \mathrm{hr} \mathrm{PF}$, showing HRP-labeled retinal axons in their dorsocaudally directed course along the optic tract towards tectum. Five leading axons (arrow) are already close to the tectum. They are followed by 2 groups of axons at a distance of about 70 and $120 \mu \mathrm{m}$, respectively. $R$, rostral; $C$, caudal; $D$, dorsal; $V$, ventral; $m$, melanophores. Scale bar, $50 \mu \mathrm{m}$. 


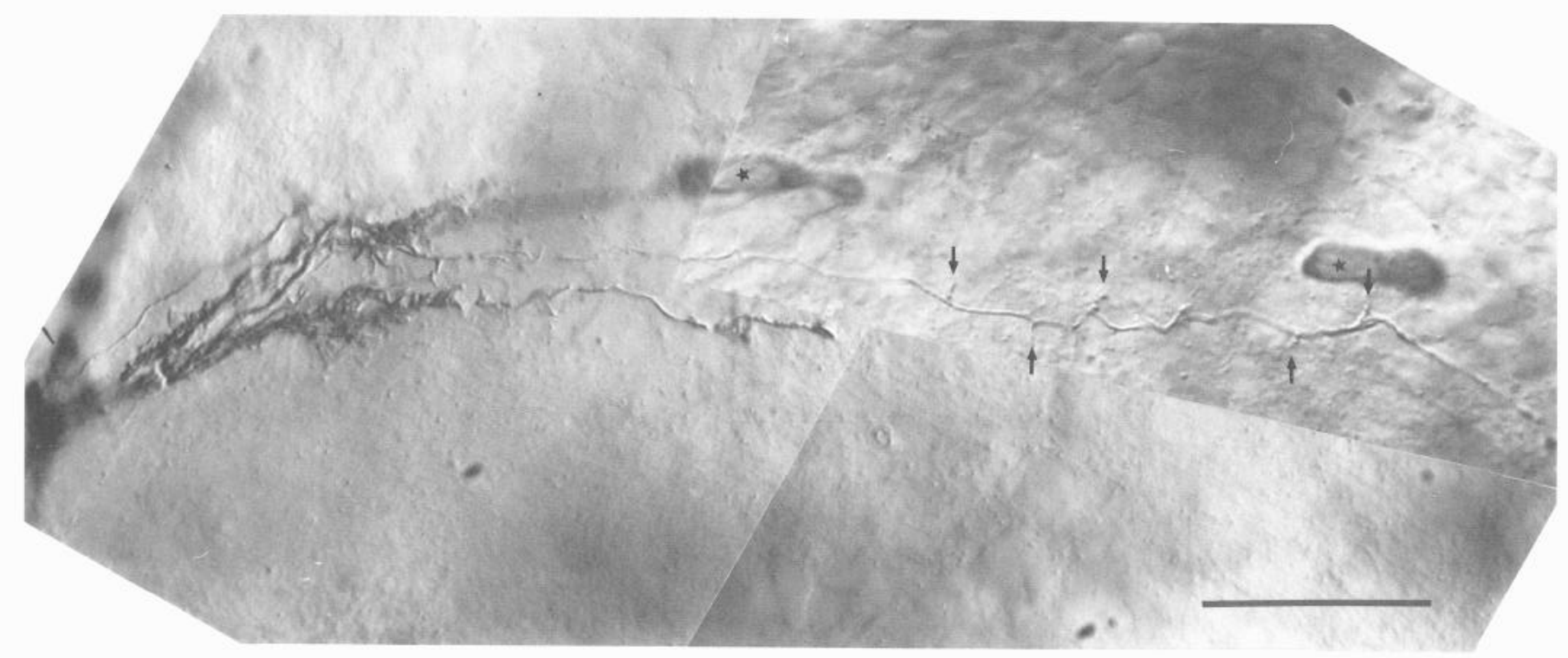

Figure 3. HRP-labeled leading axon in the optic tract close to tectum in an embryo at $46 \mathrm{hr}$ PF. This axon is followed by a front of axons at a distance of about $70 \mu \mathrm{m}$. The axon gives rise to short processes over $50 \mu \mathrm{m}$ of its length (arrows). Stars indicate erythrocytes. Scale bar, $25 \mu \mathrm{m}$.

arrive at the rostral pole of tectum at $46-48 \mathrm{hr} \mathrm{PF}, 3-4 \mathrm{hr}$ prior to the follower axons. When the $30 \%$ shrinkage of the tissue caused by fixation and dehydration is taken into account, the first axons have covered a distance of $440 \mu \mathrm{m}$ in about $12 \mathrm{hr}$; thus, they have traveled approximately $37 \mu \mathrm{m} / \mathrm{hr}$.
In DAB-reacted brains the tectum is quite distinct. At $46 \mathrm{hr}$ $\mathrm{PF}$ and at all subsequent embryonic stages, the tectum consists of 2 domains - a core, which appears in a darker brownish tone and encompasses the tectal neuropil, and a peripheral zone, which bounds the core medially, caudally, and laterally (Figs.

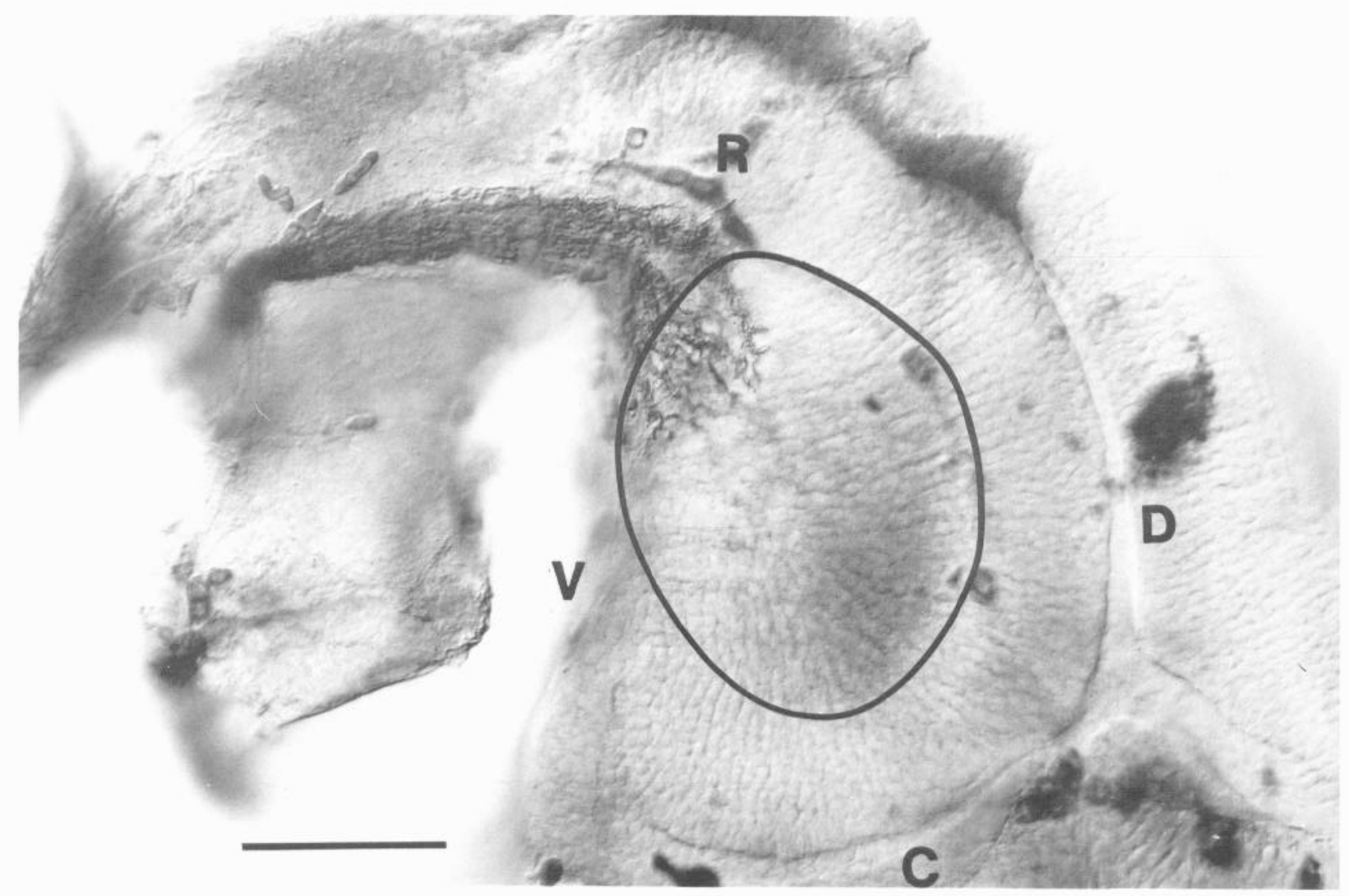

Figure 4. HRP-labeled axons $50 \mathrm{hr}$ PF in a whole mount of the brain (lateral view). Axons have invaded into the rostral tectal neuropil. The black line delineates the tectal neuropil. Abbreviations $R, C, D$, and $V$ as in Figure 2. Scale bar, $50 \mu \mathrm{m}$. 


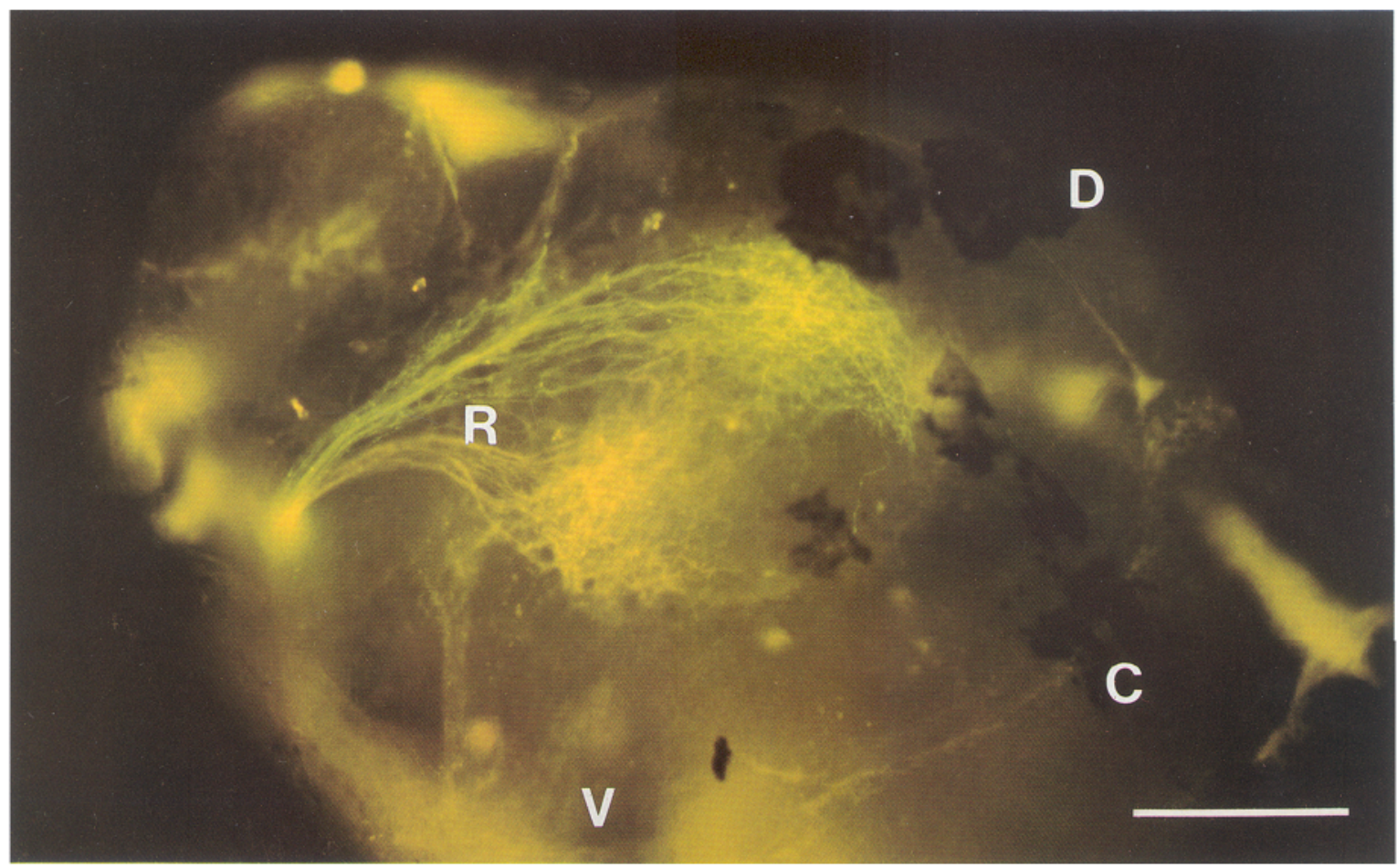

Figure 5. Whole mount of an embryonic brain (dorsolateral view) at $72 \mathrm{hr}$ PF. The green fluorescent (diO-stained) axons from the nasal quadrant of the ventral retina enter through the dorsolateral brachium of the optic tract and end retinotopically in a cluster in the dorsocaudal tectal neuropil. The yellow fluorescent (diI-stained) axons from the temporal quadrant of the dorsal retina pass into tectum through the ventrolateral brachium of the tract and terminate in a cluster in the retinotopic rostroventral tectal neuropil. Abbreviations $R, C, D$, and $V$ as in Figure 2 . Scale bar, $100 \mu \mathrm{m}$.

4, 5). The tectal neuropil can also be easily discerned under fluorescent light, appearing slightly brighter than the boundary zone (Figs. 5, 6, 8, 9). The retinal axons are restricted to the neuropil of the core region (Figs. 5, 7). The boundary zone consists of cells with long radially oriented processes, which are sometimes stained by transfer of the fluorescent dyes or HRP from axons. The extent of the tectum and the core regions was measured in 10 embryos at each of the following time points. At $46-48 \mathrm{hr}$ PF, the tectum is on average $209 \mu \mathrm{m}$ long and 155 $\mu \mathrm{m}$ wide, and the core region is about $160 \times 103 \mu \mathrm{m}$. Thus, the area of the core comprises $51 \%$ of the total tectal area. The core does not grow significantly up to $58 \mathrm{hr} \mathrm{PF}$ but has enlarged to $206 \times 132 \mu \mathrm{m}$ by $70-72 \mathrm{hr} \mathrm{PF}$ and to $220 \times 143 \mu \mathrm{m}$ by $100-120 \mathrm{hr}$ PF. The ratio of the core area to the total tectal area does not change significantly during these periods.

The first axons invade rostrally into the core region. They proceed in a more or less caudal direction, acquiring on occasion windy trajectories as they pass around cell bodies in their paths. The axons carry growth cones at their tips, and they emit short side branches with or without growth cones. With time, many more axons move into tectum (Fig. 4) and cover the rostral tectal half by $54-56 \mathrm{hr}$ PF. The caudal tectal half remains uninnervated up to this time, but then axons gradually proceed into the caudal tectal region over the next $12 \mathrm{hr}$ PF. The core region is densely filled by axons at $70-72 \mathrm{hr} \mathrm{PF}$ in its total extent. As a rough approximation we calculated the mean velocity of axonal growth over the neuropil of the tectum from the time at which the first axons arrive to the time at which axons reach the caudal tectal end (distance, corrected for $30 \%$ shrinkage, $248 \mu \mathrm{m}$ in 24-26 hr) and found an average of 9.5$10.3 \mu \mathrm{m} / \mathrm{hr}$.

\section{Spatial order of retinal axons in the optic nerve and tract}

In the Xenopus embryo the dorsal retina contains a set of axons that are the first to navigate the pathway to tectum (Holt and Harris, 1983). To determine whether axons from a defined sector in retina pioneer the path to tectum in zebrafish, crystals of the fluorescent dyes diI and diO were placed at $34 \mathrm{hr}$ PF into one eye in opposite sides, i.e., either into dorsal versus ventral or into nasal versus temporal retina. The relative order of the yellow and green fluorescent axons in the optic tract was examined in embryos at $40-50 \mathrm{hr} P F(N=50)$.

In none of these combinations did we find one specific group of axons to be consistently ahead of the others. Either yellow (diI stained) and green (diO stained) axons were mixed and equally far advanced, or yellow axons led green axons, or green axons led yellow axons. Thus, the temporal order in which axons from retinal sectors grow into the nerve and tract appears to be random.

Using reconstructions of serial ultrathin sections of axon fascicles in the $50 \mathrm{hr}$ PF embryo, Bodick and Levinthal (1980) found that axons from neighboring ganglion cells travel together in the optic nerve. We confirmed their results by staining dorsal versus ventral or nasal versus temporal axons with diI and diO. We extended Bodick and Levinthal's findings further by testing the spatial order of the axons in the tract. Dorsal and ventral axons occupy separate aspects throughout the entire nerve, as well as in the tract (Fig. 5). At the brachial bifurcation of the tract, dorsal and ventral axons are bodily segregated and proceed towards the dorsal and ventral halves of tectum (Fig. 5). Nasal axons are separated from temporal axons in the nerve, but they are mixed in the tract on their path to tectum (Figs. 6, 8). 


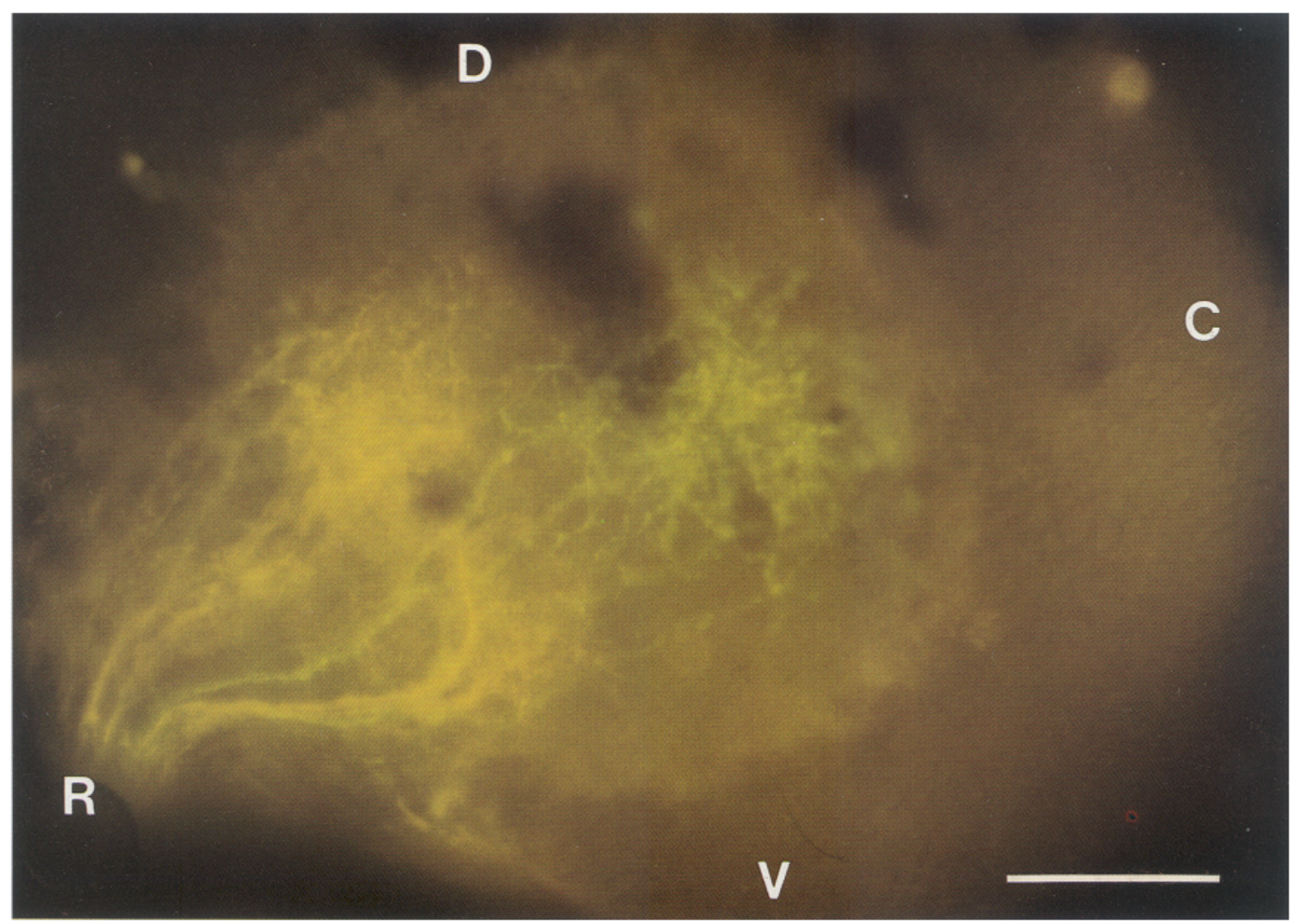

Figure 6. Whole mount of brain at $72 \mathrm{hr}$ PF (dorsal view). Green fluorescent (diO-stained) axons from nasal retina pass over the rostral half of the tectal neuropil, which is innervated by yellow fluorescent (diI-stained) axons from the temporal retina and terminate in the caudal half of the tectal neuropil. Abbreviations $R, C, D$, and $V$ as in Figure 2. Scale bar, $50 \mu \mathrm{m}$.

\section{Spatial order of retinal axons in tectum}

The development of the tectal projection was pursued with a labeling procedure similar to that described above, except the relative order of the diO- and diI-labeled axons was examined at 52-58 and 70,72, and $80 \mathrm{hr} \operatorname{PF}(N=55)$. If the projection is retinotopic and precise, the diI- and diO-labeled axons should occupy separate and predictable sites in tectum. If the projection is not retinotopically organized, both types of labeled axons should be intermixed and should be distributed widely over the tectal surface. As shown in the first experiments of this study, by $70-72 \mathrm{hr}$ PF axons have filled the rostrocaudal and mediolateral axes of the tectal core region. The spatial order of the projection at this time is considered first.

Figure 5 illustrates a tectum with diI (yellow) and diO (green) axons originating from ventral and dorsal retina, respectively. Entering through the ventrolateral brachium, dorsal retinal axons pass almost exclusively into the ventrolateral tectum and end rostrally in a patchlike region. Ventral retinal axons course from the dorsomedial brachium into tectum and end in a patch in the caudal dorsomedial tectum. The rostral or more caudal location of these patches within each hemitectum always depended on whether the dye crystals had been introduced into the more temporal or more nasal aspects of the dorsal and ventral hemiretina, indicating that temporal and nasal axons are localized to retinotopic sites at $70-72 \mathrm{hr}$ PF. This was confirmed when nasal axons were labeled with diO and temporal axons with diI (Fig. 6). Temporal axons are situated in the rostral tectum, and nasal axons are seen to run over the rostral tectum and to end in caudal territories. Thus, at the time at which the axons have innervated the tectal neuropil, axons derived from defined retinal quadrants end in retinotopic quadrants of the tectum. A similar retinotopic order was found in tecta at $80 \mathrm{hr}$ PF.

The retinotopic order of the projection at 70-80 and at 100 $120 \mathrm{hr}$ PF was confirmed when HRP was applied to retinal quadrants $(N=32)$. Figure $7 a$ shows HRP-stained temporal axons at $72 \mathrm{hr}$ PF. They form a dense meshwork in the retinotopic rostral tectum. Nasal axons at $72 \mathrm{hr}$ PF travel over the rostral tectum and branch and arborize in the caudal tectum (Fig. 7b).

We determined how this retinotopic order develops between the time at which axons enter into tectum and after they had grown to fill the complete extent of the tectal core region. The distribution of diI- and diO-labeled axons from dorsal and ventral and nasal and temporal retina was investigated between 52 and $58 \mathrm{hr} \mathrm{PF}(N=17)$. At $56 \mathrm{hr}$ the dorsal and ventral axons are located in their appropriate ventrolateral and dorsomedial tectal halves, but they are there confined to the rostral hemitectum. The temporal and nasal axons at 52-56 hr are restricted to and coextensive over the rostral tectum. From about 56-58 hr on the nasal axons, but not the temporal ones, were seen to have grown beyond the rostral tectum and to have advanced into the anterior portion of the caudal tectal half (Fig. 8). These findings indicate that dorsal and ventral axons directly innervate their separate dorsomedial and ventrolateral tectal halves. The retinotopic order in the rostrocaudal tectal axis is created by a caudally directed selective progression of the nasal axons.

To investigate whether temporal axons in the rostral tectum at $56 \mathrm{hr} \mathrm{pF}$ are ordered on a fine scale by their radial retinal origin, diI was placed either into the peripheral-most or the 

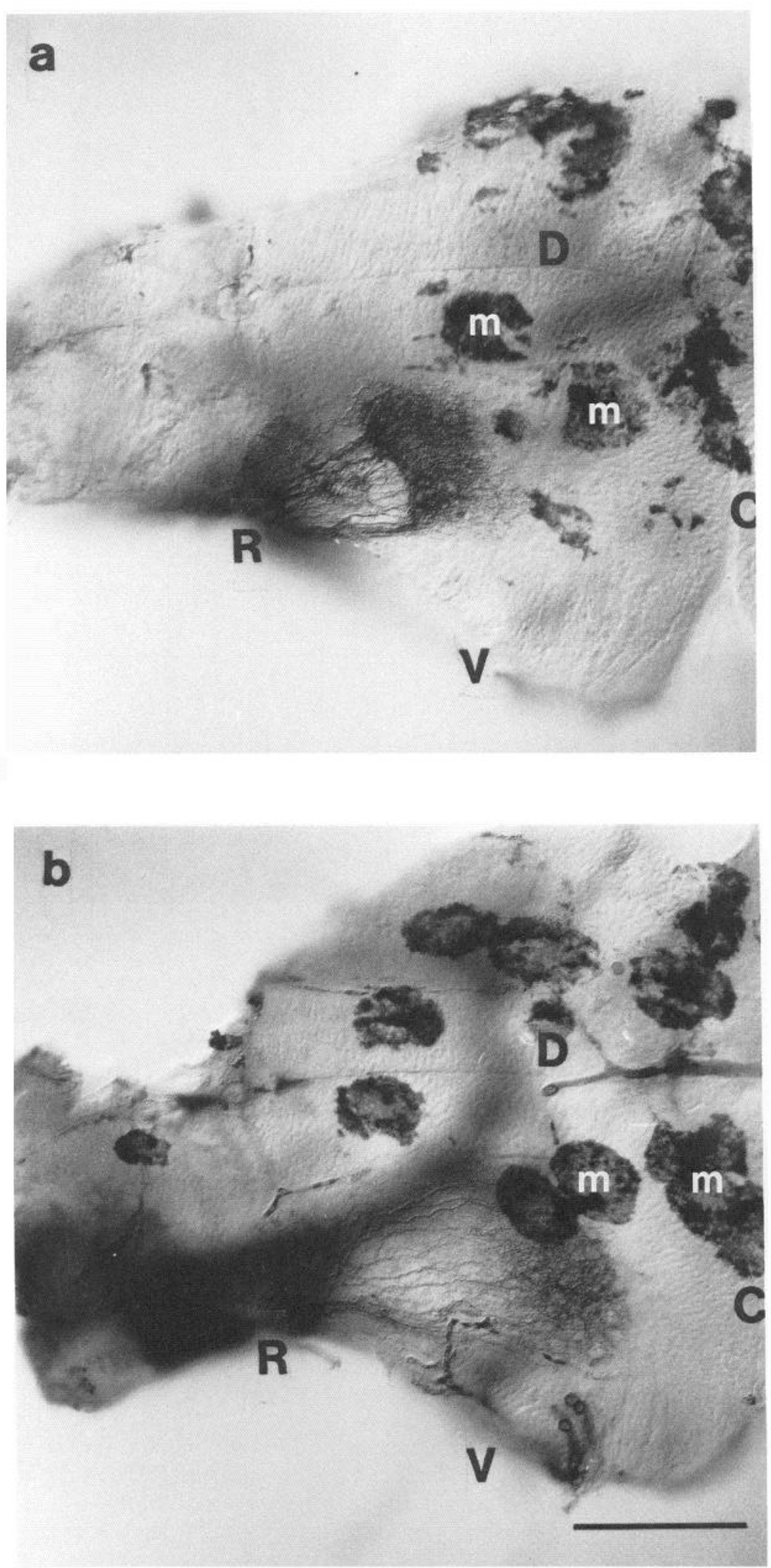

Figure 7. Two whole mounts of embryonic brains at $72 \mathrm{hr} P F$ (dorsal view) showing the path of HRP-labeled axons in tectum after application of HRP to the temporal $(a)$ and nasal $(b)$ retina, respectively. $a$, Axons derived from temporal retina are restricted to the rostral half of the tectal neuropil. $b$, Nasal retinal axons pass over the rostral half of the tectal neuropil and terminate in a dense meshwork in the caudal tectal half. Abbreviations $R, C, D, V$, and $m$ as in Figure 2. Scale bar, $100 \mu \mathrm{m}$. more central aspects of the temporal retina at $34 \mathrm{hr} \mathrm{PF}(N=$ 29). In Figure 9, $a$ and $b$, the distributions of diI-stained peripherotemporal and centrotemporal axons are compared, and they can be seen to occupy rostroperipheral and rostrocentral portions of the tectum preferentially. This indicates that the temporal axons occupy their appropriate retinotopic sites at times at which the nasal and temporal axons are coextensive over rostral tectum. 


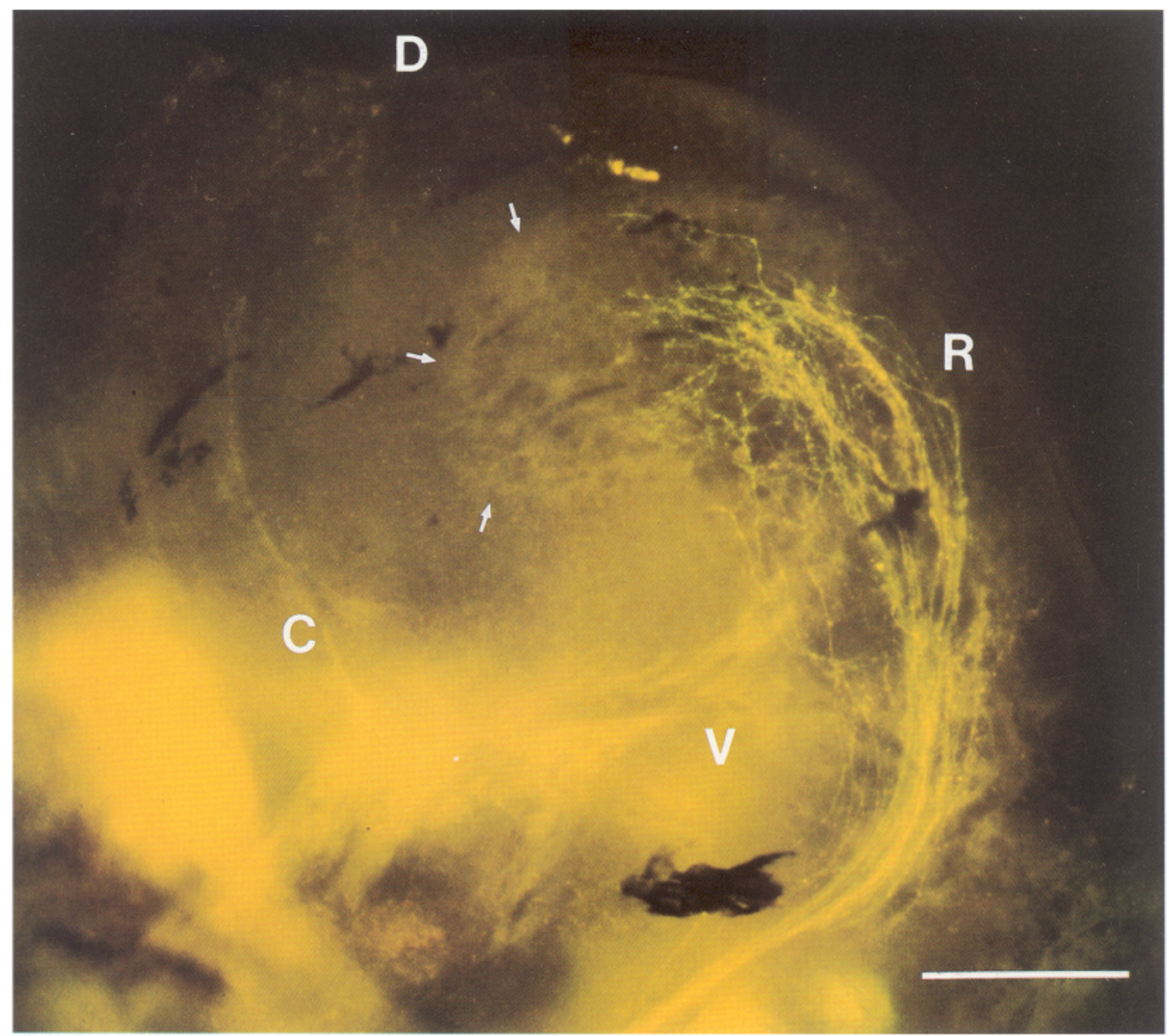

Figure 8. Whole mount (dorsolateral view) of an embryonic brain at $58 \mathrm{hr}$ PF. The green fluorescent (diO-stained) and the yellow fluorescent (diI-stained) axons derived from the temporal and nasal retina, respectively, are mixed in the optic tract as well as over the rostral half of the tectal neuropil. The green axons from nasal retina are further advanced than the yellow temporal axons and have invaded into the anterior portion of the caudal tectum. Arrows indicate the border between the tectal neuropil and the boundary region. Abbreviations $R, C, D$, and $V$ as in Figure 2 . Scale bar, $100 \mu \mathrm{m}$.

\section{Preference of embryonic axons for their retinotopically appropriate hemitectum}

Two alternative mechanisms can account for the progression of the nasal axons into caudal tectal domains: either nasal axons possess a preference for the caudal tectal neuropil, or they grow into the vacant caudal regions since the rostral tectal half is rapidly occupied by temporal axons.

A classical approach to determining which of these alternatives actually occurs is to observe the growth of the nasal axons in the absence of temporal axons (and vice versa) (Attardi and Sperry, 1963). Thus, the temporal or nasal half of the eye was surgically removed at $30 \mathrm{hr} P F$. Since the ablated half is replaced within 12-20 hr, the surgery was repeated at $48 \mathrm{hr}$ PF. In one set of experiments, a crystal of diI was introduced into the remaining hemiretina at $54-56 \mathrm{hr} \mathrm{PF}$, and the fish were killed at $70-72 \mathrm{hr}$ PF $(N=12)$. In a second experiment, HRP was applied to the half retina at $70-72 \mathrm{hr} P F(N=22)$. Figure $10 b$ shows the diI-labeled nasal axons at $72 \mathrm{hr}$ PF. They are seen to travel in bundles over the rostral tectum and to arborize in the caudal tectal half. This suggests that the nasal axons may have a specific preference for the caudal tectum since they bypass the rostral tectum even when this half is devoid of temporal axons.

Using a similar experimental protocol, ablations of the nasal retina were used to determine if temporal axons might spread into caudal tectum when nasal axons are absent $(N=13)$. The results of this experiment are illustrated in Figure 10a. Temporal axons labeled with diI (Fig. 10a) or with HRP (not shown) were restricted to the rostral tectal half and did not grow into the vacant caudal tectum. This result supports the view that temporal axons possess a preference for terminating in rostral tectal territories.

A restriction to their appropriate medial or lateral hemitectum was also observed for the ventral and dorsal axons when either the dorsal or ventral retina was ablated $(N=18)$. Two tecta, one with ventral axons stained with diI, the other with HRPlabeled dorsal axons, are shown in Figures 11 and 12. In Figure 11 the labeled ventral axons are confined to the dorsomedial tectum. Ventral axons in the absence of dorsal axons (Fig. 11) or dorsal axons in the absence of ventral axons (Fig. 12) travel towards tectum through their appropriate brachium of the optic tract. This suggests that guidance cues must already be available to the axons before they enter the tectum.

\section{Comparison between the embryonic and adult retinotectal projection}

To gain an estimate of the precision of the retinotectal projection in embryos compared with that in adult zebrafish, the area of 
The Journal of Neuroscience, December 1988, 8(12) 4521
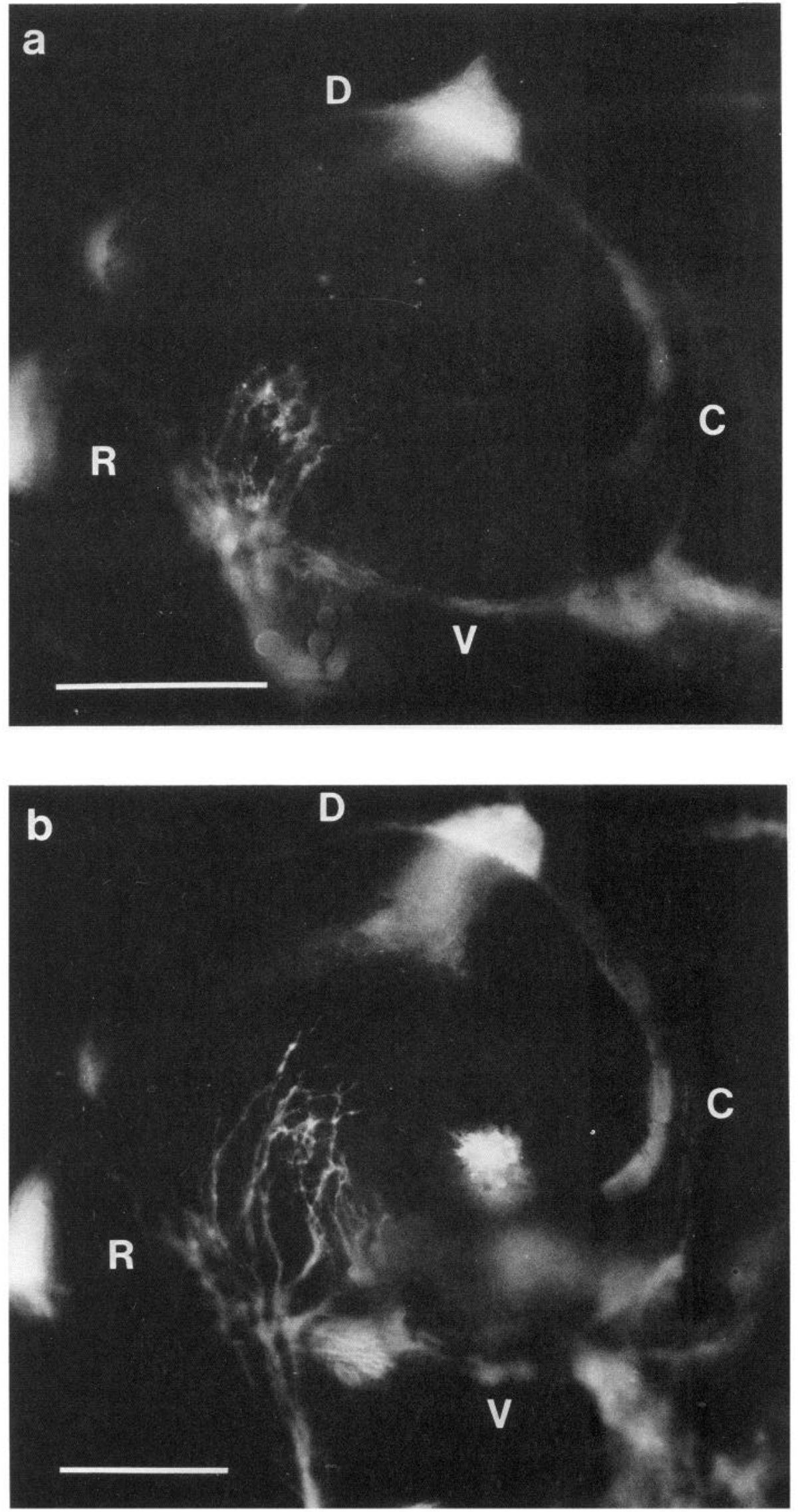

Figure 9. Whole mounts of brains at $54 \mathrm{hr}$ PF (dorsolateral view). The endings of the dil-stained axons from peripherotemporal retina are located retinotopically in the rostroperipheral aspect of the tectal neuropil $(a)$, whereas axons from centrotemporal retina are situated in more midtectal regions $(b)$. Abbreviations $R, C, D$, and $V$ as in Figure 2 . Scale bars, $100 \mu \mathrm{m}$. 

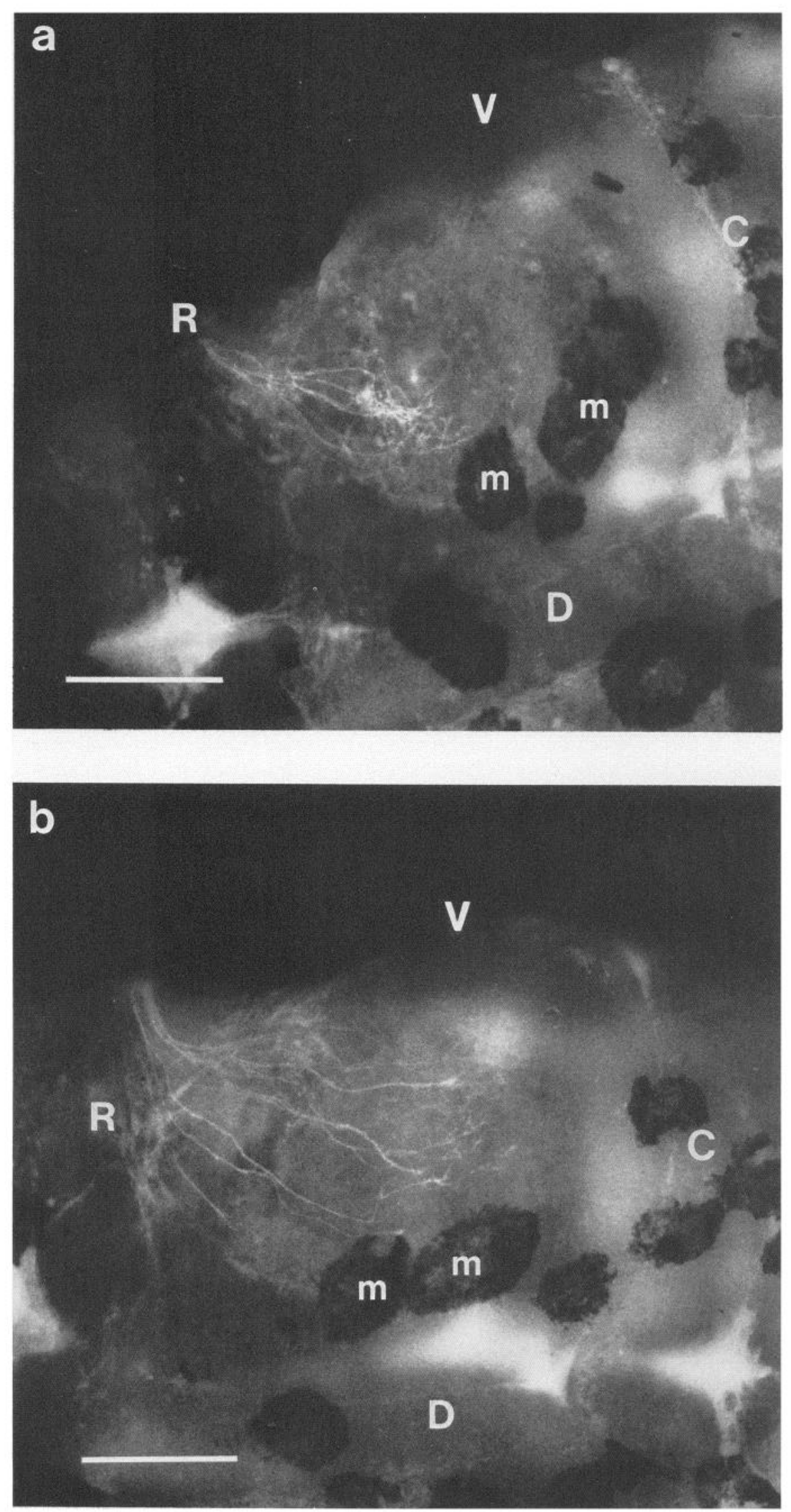

Figure 10. Retinal axons stained with diI in 2 tecta at $72 \mathrm{hr}$ PF (dorsal view). $a$. After surgical removal of the nasal retina at $30 \mathrm{hr} \mathrm{PF}$, the temporal axons remain restricted to the rostral portion of the tectal neuropil and have not invaded into the caudal tectum. $b$, After ablation of the temporal retina at $30 \mathrm{hr}$ $\mathrm{PF}$, nasal axons traverse the rostral tectum to end in the caudal tectal neuropil. $m$, melanophores; abbreviations $R, C$, $D$, and $V$ as in Figure 2. Scale bars, 100 $\mu \mathrm{m}$. 


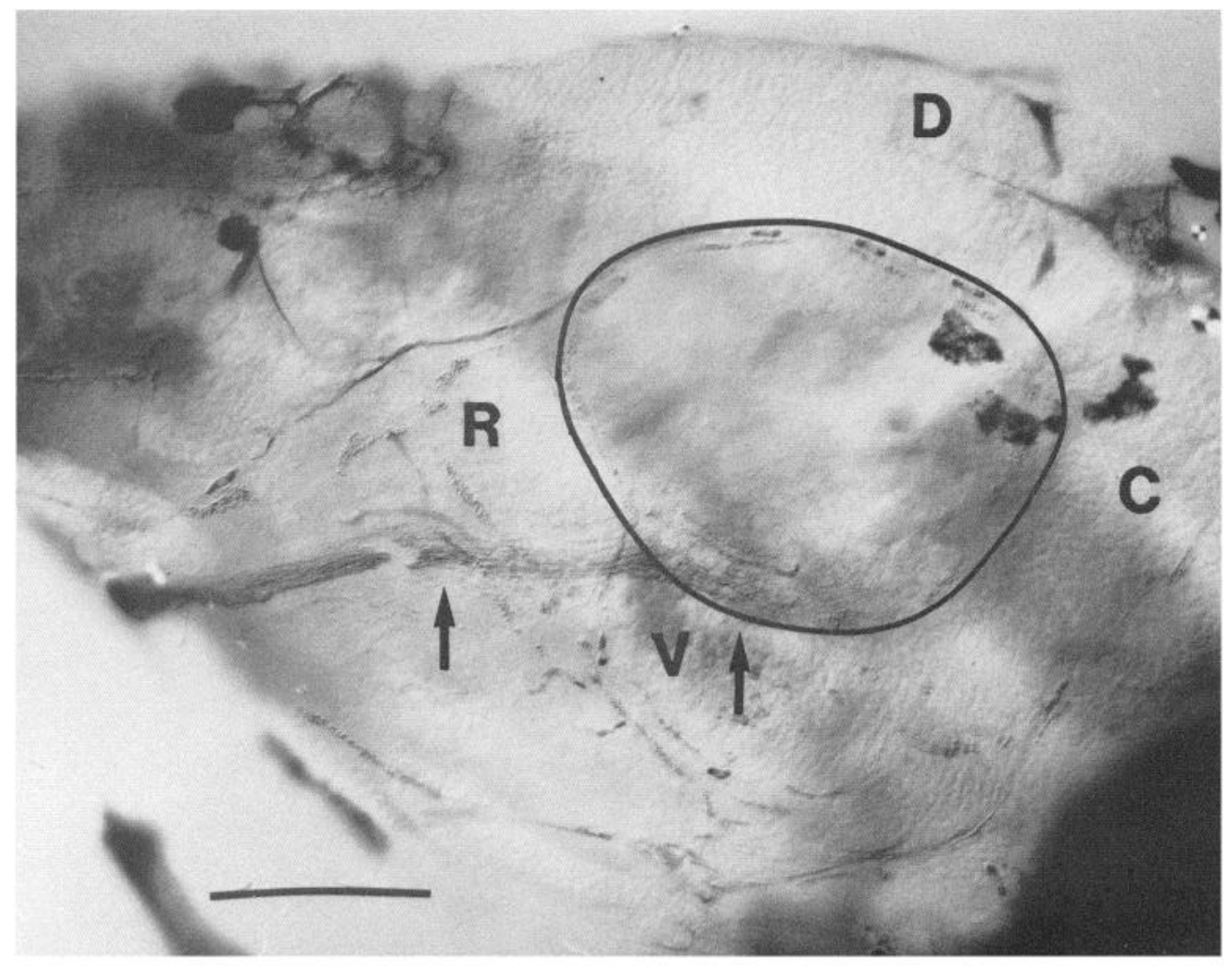

Figure 11. Whole mount of an embryonic brain at $70 \mathrm{hr}$ PF (dorsolateral view). After ablation of the ventral retina at $30 \mathrm{hr} \mathrm{PF}$, the HRP-stained axons (arrows) from the dorsal retina course selectively through the ventrolateral brachium of the tract into the ventral half of the tectal neuropil. The tectal neuropil is encircled by a black line. Abbreviations $R, C, D$, and $V$ as in Figure 2. Scale bar, $100 \mu \mathrm{m}$. tectum over which terminal arbors extend their branches (tectal coverage) was determined. After global or local applications of HRP to the retina, the tecta contained one or more well-stained terminal arbors, which could be traced throughout their extent into their fine-caliber branches. As in goldfish (Stuermer, 1984), the terminal arbors in zebrafish are flattened and elongated in a horizontal plane within the tectal neuropil. Typical examples of small and large terminal arbors in the embryo at 70-72 $\mathrm{hr}$ PF (Fig. 13, $a, b$ ) and adult (Fig. 13, c, d) are illustrated.

Arbors in tecta of embryos at 54-55, 70-72, and 100-120 hr

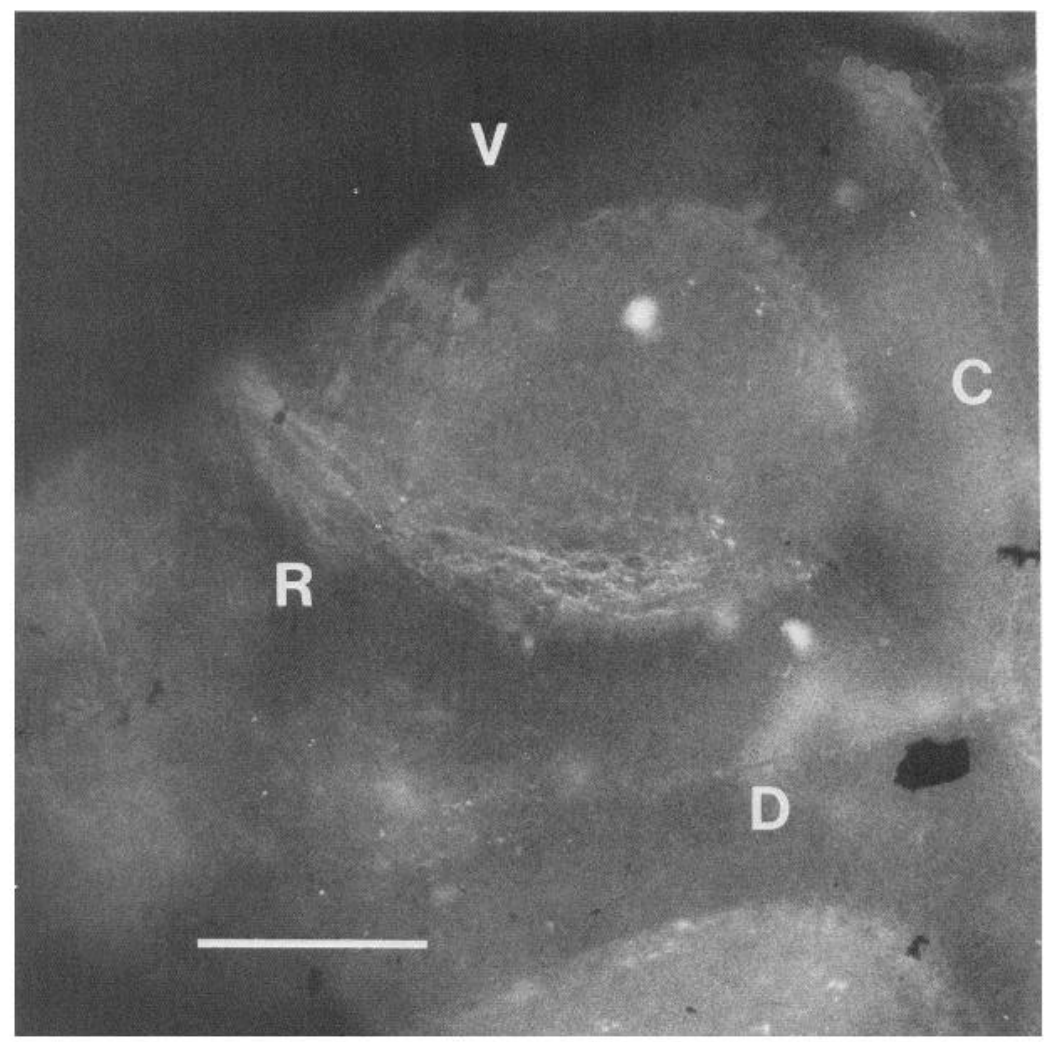

Figure 12. Whole mount of an embryonic brain at $70 \mathrm{hr}$ PF (dorsolateral view). Dorsal retinal axons (stained with dil) in the absence of ventral axons travel selectively into the ventral portion of the tectal neuropil. Abbreviations $R, C, D$, and $V$ as in Figure 2 . Scale bar, $100 \mu \mathrm{m}$. 
a
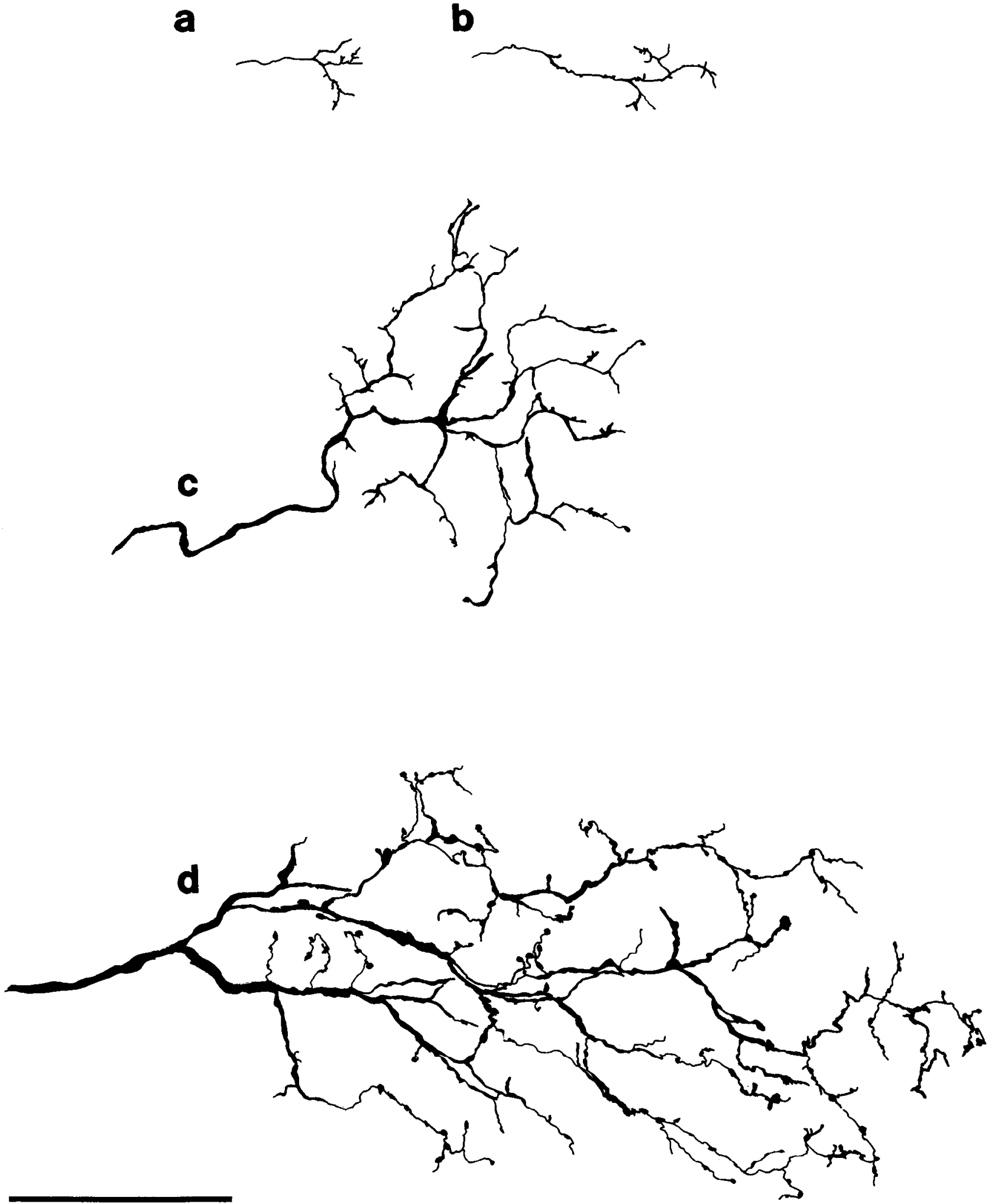

Figure 13. Camera lucida tracings showing examples of a small (a) and a large (b) arbor of embryos at 70-72 hr PF and a medium-sized (c) and large $(d)$ arbor of an adult zebrafish. Scale bar, $50 \mu \mathrm{m}$.

$\mathrm{PF}$ and in adults were measured by encircling the arbor from its first branch point to the tips of the longest branches by a smooth line and by determining its "long" and "short" axes. The arbors long axis is defined as the continuation of the stem axon, whereas the short axis is perpendicular to the long axis (Stuermer, 1984). Embryonic axons often exhibited small processes of about $3-5 \mu \mathrm{m}$ in length in addition to more prominent and longer branches (Fig. 13a). Since it is impossible to tell 


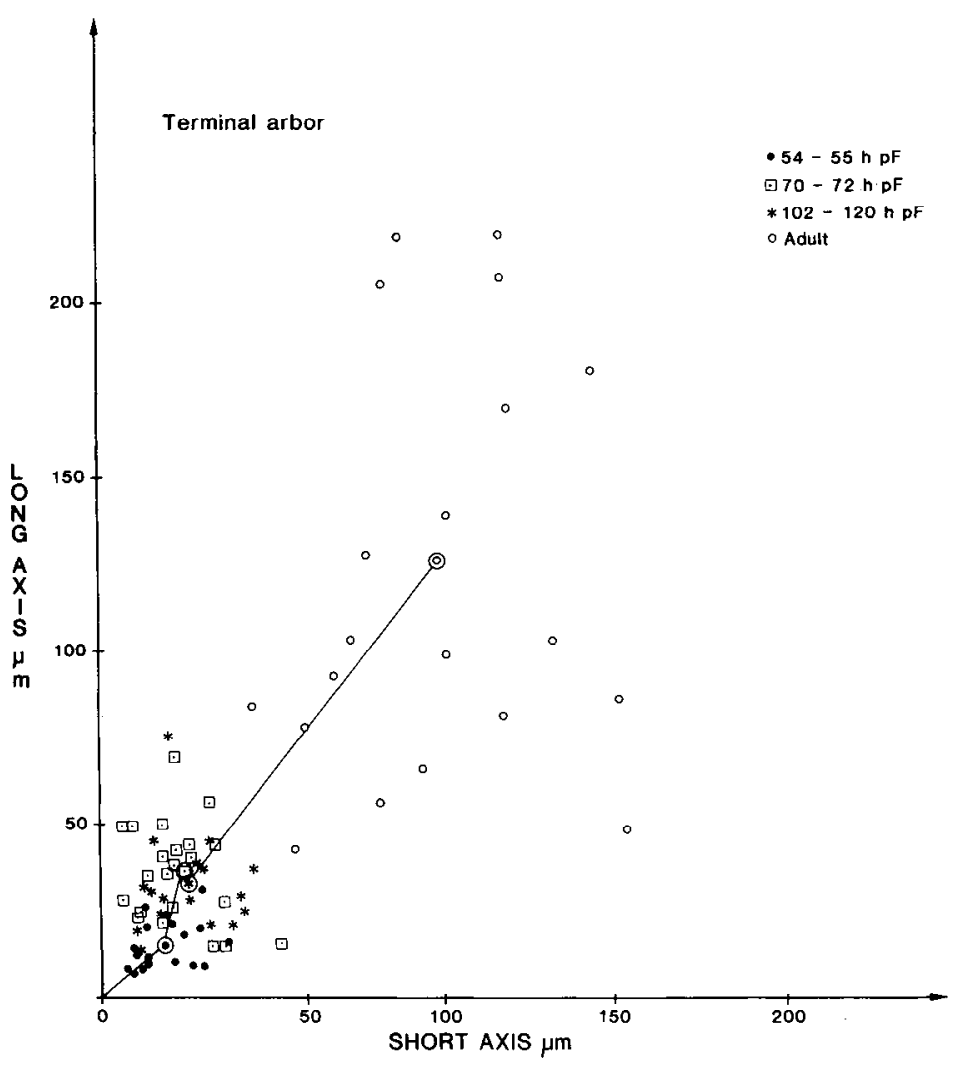

Figure 14. Plot of the terminal arbor long and short axes of embryos of 54 $55,70-72$, and 102-120 hr PF and of adults. The graph connects the means (circled symbols) of the arbor axes from each age group.

whether these processes are remnants of retracted branches or growth cones or are sites of new branch extensions, these processes were included in our measurements. The area of the arbors and that of the tecta were approximated by an ellipse. The axons are restricted in the embryo to the tectal core region, so that only this region was taken into account for our measurements.

The long and short axes of the arbors at different ages are plotted in Figure 14. They increase with age. Therefore, the arbor area, defined by the ellipse, increases as well. In the adult the arbor area is 39 times larger than in the 54-55 hr PF embryo and 15 times larger than in the 70-120 hr PF embryo. These measurements represent only a rough estimate of the arbors' growth with age. As visible in Figure 13, the arbors in adults possess many more processes than those in the embryos. Therefore, the sites of effective contacts with tectal cells are probably magnitudes higher in the adult than in the embryo.

The tectum enlarges with increasing age and is 137 times larger in the adult than the core region at $72 \mathrm{hr}$ PF. In the adult the tectum is covered by retinal afferents throughout its whole extent, so that there is no core region and boundary zone. The arbor area in relation to the tectal area is shown in Figure 15, and the shape of the curve documents the arbors' and tectal growth. The values of the arbor areas and tectal areas were used to calculate the tectal coverage, that is, the percentage of the tectum occupied by a mean-sized arbor. As documented in Figure 16, the tectal coverage of the arbors is similar between 54 55 to $100-120 \mathrm{hr}$ PF (average, $2.8 \%$ ), but it falls to $0.4 \%$ in the adult. Thus, in adults, the terminal arbors occupy a 7 times smaller percentage of the tectum than in embryos. This appears not to be caused by a decrease in arbor size since they seem to grow. Instead, the tectal area enlarges to a relatively greater extent than the arbors. A similar process has been observed in Xenopus (Sakaguchi and Murphey, 1985).

\section{Discussion}

This study has established the spatiotemporal order in the development of the retinotectal pathway in the zebrafish embryo. In contrast to the early diffuse projection in goldfish regenerates, the developing retinotectal projection is both precise and retinotopically organized. This retinotopic order is seen along the rostrocaudal and dorsoventral axis of the tectal neuropil at 70 $72 \mathrm{hr} \mathrm{PF}$, that is, at times when axons have innervated the available tectal neuropil. Prior to this, dorsal and ventral axons entering through separate brachia of the optic tract occupy separate and retinotopic aspects of the rostral tectal half. Nasal and temporal axons, on the other hand, are mixed in the tract and are coextensive over the rostral tectal half. They segregate to occupy distinct tectal domains by a selective progression of the nasal axons into caudal tectal regions. After removal of the nasal or temporal retina, axons from the remaining half grow to and branch selectively in their retinotopically appropriate halves of tectum, suggesting that nasal and temporal axons possess a differential affinity for their retinotopically appropriate tectal domains.

The tectal coverage of terminal arbors in the embryo is $2.8 \%$, thus 7 times larger, on average, than in the adult. The decrease in tectal coverage is a result of an increase in arbor size concurrent with an even larger increase in tectal arca. The embryonic retinotectal projection differs from the regenerated projection in goldfish, in which numerous axons are misrouted and branch transiently at inappropriate regions of tectum. 

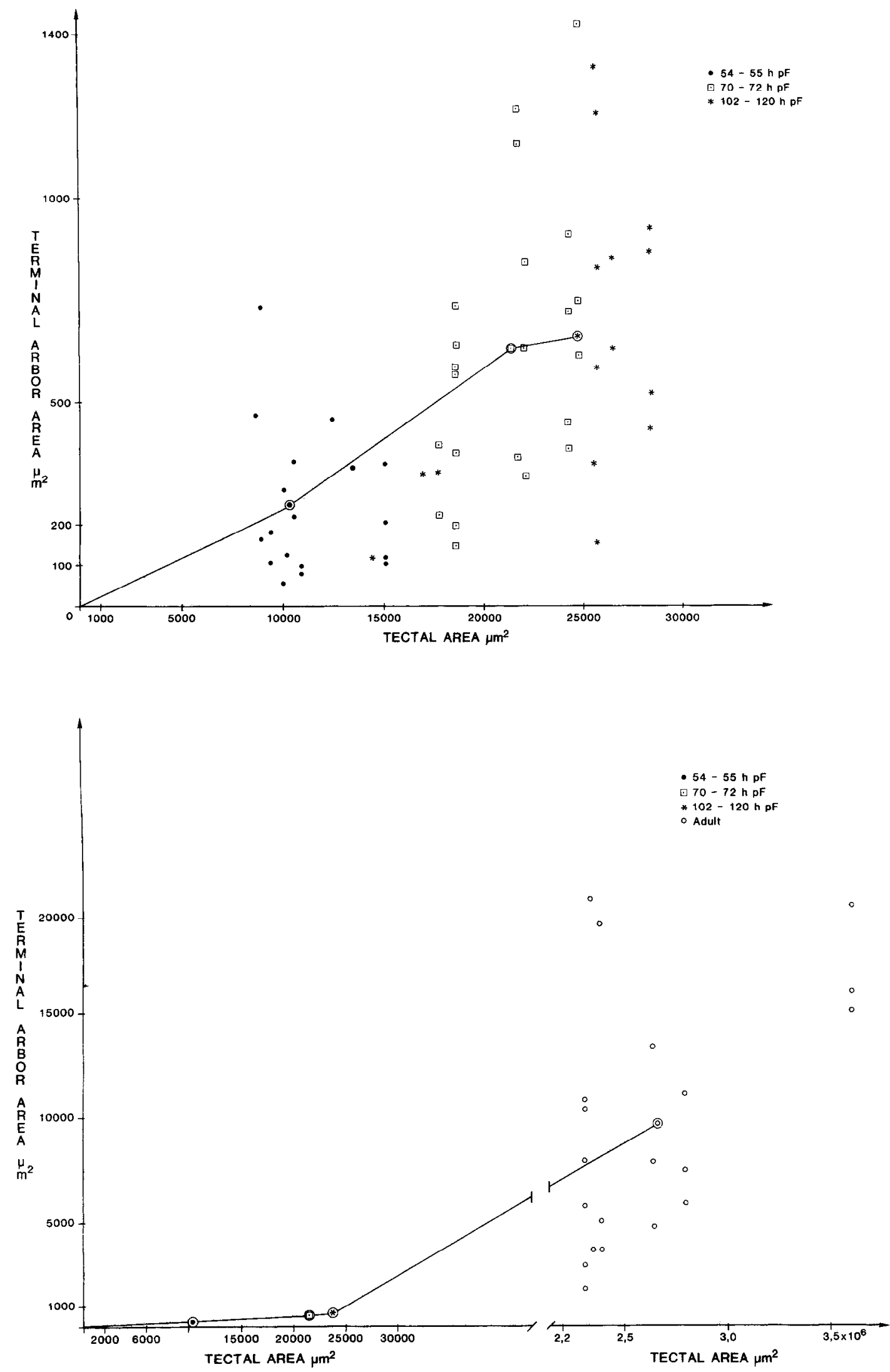

Figure 15. Top, Relation between the area covered by individual arbors and the area of the tectal core region or neuropil. The graph connects the means (circled symbols) of the values for the different embryonic ages. Both, the area over which axons extend their arbors and the tectal area increases from younger to older embryos. Bottom, To document that arbor and tectal area grow into adulthood, this graph combines the means (circled symbols) of arbor/tectum area relation for the embryos on a reduced scale with the data points of the adults. 


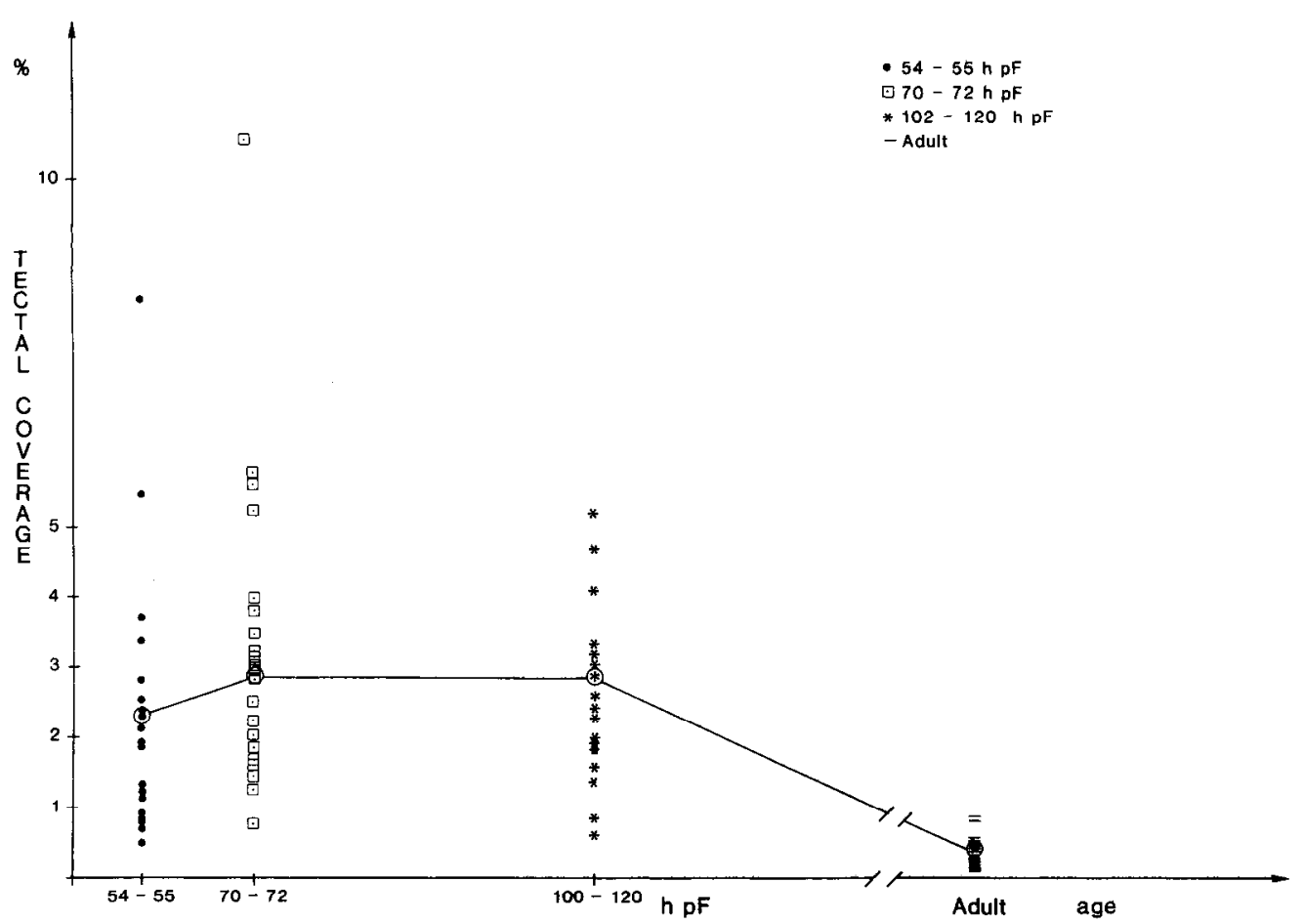

Figure 16. Graph illustrating that the tectal coverage of the terminal arbors declines from embryonic ages to adulthood. Solid line connects the means (circled symbols) of the tectal coverage values at 55, 70-72, 102-120 $\mathrm{hr} \mathrm{PF}$ and in adults.

\section{Technical considerations}

The foregoing results were achieved by following the distribution of labeled retinal axons which were either stained with HRP or with the fluorescent dyes dil and diO. In earlier experiments (Stuermer, 1988a, b), we succeeded in labeling growing axons and their growth cones during optic nerve regeneration in adult goldfish. This was done by applications of HRP to severed axons in retina 4-5 d prior to sacrifice of the fish. Satisfactory staining of embryonic axons proved to be more difficult, first because they are of extremcly finc caliber $(0.1-0.5 \mu \mathrm{m})$ (Bodick and Levinthal, 1980) and, second, because the early axons degenerate rapidly if the ganglion cells and their retinal axons are injured. Thus, in embryos younger than 70-72 hr PF, we introduced an HRP-coated needle into the eye cup to avoid injuring the retina and waited for the HRP to dissolve away from the needle. Using embryos of 70-72 $\mathrm{hr}$ and older, it was possible to poke an HRP-coated needle into defined sites of retina without causing noticeable signs of axonal degeneration. We searched systematically for the optimal survival time that would yield an intense staining of the axons and would not cause degeneration of the axons (Harris et al., 1985). An interval of $30 \mathrm{~min}$ between HRP application and sacrifice of the fish proved to give densely labeled axons and guaranteed a preservation of growth cones and filopodia. We cannot exclude the possibility that axons might have undergone morphological degenerative changes due to the HRP application. However, HRP-stained axons in embryos exhibited morphologies similar to axons stained with the fluorescent dyes diI and diO. These fluorescent dyes of the carbocyanine group had been used in several recent reports to stain growing axons in vivo and in vitro and were found not to exert toxic affects on the axons (Schwartz and Agranoff, 1981; Honig and Hume, 1986; Harris et al., 1987; Thanos and Bonhoeffer, 1987). In our experiments, diI- and diO-stained axons reached the rostral pole of tectum and its caudal end, respectively, at times comparable to those found for HRP stained axons, confirming that dil and diO applied to cells and axons does not interfere with the normal growth rate of the axons (Harris et al., 1987; Stuermer and Vielmetter, 1987a; Thanos and Bonhoeffer, 1987).

The fluorescent dyes have to be brought into physical contact with the neurons and are most likely incorporated into the membranes and transferred to the axons and growth cones (Honig and Hume, 1986; Thanos and Bonhoeffer, 1987). Since these dyes are insoluble in water, they are suited to staining a small and defined group of cells and axons. Thus, it was possible to label simultaneously axons from 2 defined regions within one retina with different colors (diI and diO) and to observe the relative order of the labeled axons in the axonal pathways.

With local applications of HRP we successfully labeled axons from approximately a third to a half of the retina in 70-72 $\mathrm{hr}$ and older embryos. Prior to this time, similar HRP applications gave staining of nearly all axons (part of which were heavily labeled, part of which were more lightly labeled), suggesting that HRP might diffuse more rapidly in less mature retinae.

HRP is superior to the fluorescent dyes for determining the time at which the first axons appear in the optic nerve. Since it is not known where in the retina the axons originate, it is necessary to use global application of a dye such as HRP, which stains most or all axons from retina. It was difficult to detect the very first few pioneer axons in the optic nerve in whole mounts of the brain, since unlike in the tract or on tectum, where axons run close to the pial surface, they travel deeply embedded in surrounding tissue in the nerve. Therefore, we used vibratome sections to visualize the HRP-stained pioneer axons. We also tried to apply diI and diO close to the ventral fissure to label the first axons. However, the attempt to identify the pioneers in vibratome sections failed since we were not able to see diI- or diO-labeled axons in such sections. Similar diffculties were encountered in work on Xenopus embryo (G. E. 
Holt, personal communication). Thus, because of these experiences, we used staining techniques, which we found to be appropriate to answer particular questions.

\section{Mechanisms of map formation}

At least 2 mechanisms appear to be involved in the proper alignment of the axonal endings in the dorsoventral and rostrocaudal axis of tcctum: prcordcring of axons in the optic nerve and tract and a preference of axons for their appropriate target sites in tectum. With local applications of the 2 fluorescent dyes diI and diO into opposite positions in retina, we found that axons in the nerve are organized by their retinal regional origin such that temporal and nasal, as well as dorsal and ventral, axons are segregated from one another. Dorsal and ventral axons proceed over separate aspects of the optic tract into the ventral and dorsal half of the tectal neuropil. Thus, the retinotopic ordering of dorsal and ventral axons in tectum can be regarded as being predetermined by the spatial order of the fiber path.

Preordering prior to the entrance into tectum does not account for the correct positioning of nasal and temporal axons in tectum. Temporal and nasal axons appear to mix in the optic tract and invade into the rostral half of tectum together. Nasal axons remain coextensive with temporal axons in the rostral tectum, i.e., in the retinotopically appropriate region for temporal axons, until they migrate into their appropriate caudal tectal region. This segregation of nasal from temporal axons could be explained without evoking any specific axon-tectum interaction if the temporal axons would arrive in tectum prior to the nasal axons. The temporal axons would settle in the tectal region that they encounter first, so that the nasal axons would have to pass them to find open synaptic sites in the caudal tectum. However, our data showed that the arrival of temporal axons in tectum does not precede that of the nasal axons. Therefore, to account for their segregation, it is most likely that nasal axons possess a preference for caudal tectal domains and temporal axons for rostral tectum. This could be mediated by a differential distribution of tectal positional markers, which are recognized by the growing axons. Further support for this view are other findings of this study: when the nasal or temporal axons were surgically removed prior to the outgrowth of axons from the eye, the nasal axons (now the first and only ones to enter the rostral tectum) bypass the open sites on rostral tectum to grow towards and settle in the caudal tectal half. They occupy the caudal tectum at normal times, supporting the idea that they did not first branch extensively in the rostral tectum and spread into caudal sites at a later time. Likewise, temporal axons, in the absence of nasal axons, remain restricted to thcir appropriate rostral tectal half and refrain from spreading into the caudal tectum.

This restriction to appropriate tectal territories of axons from nasal and temporal hemiretinae was maintained at least up to day 8 of the fish's development. Later times were not investigated. Longer survival times after retinal ablation are needed to determine whether an expansion of the half retinal projection into vacant tectal territories might occur at a later time. Such an expansion of nasal axons is reported to occur in the adult goldfish, beginning at 3-4 months after half-retinal removal (Schmidt, 1978).

Dorsal (ventral) axons in the absence of ventral (dorsal) axons are also restricted to their appropriate ventral (dorsal) hemitectum. Moreover, as shown in Figure 11, they were limited to their appropriate brachium before entering into tectum. This indicates that either chemical or mechanical guidance cues must already be available to them along their pathway. Evidence for guidance by chemical markers are experiments showing that axons from double ventral compound eyes course preferentially along their appropriate aspects of the optic tract (Fawcett and Gaze, 1982).

Although guidance along specific pathways would suffice to account for the targeting of dorsal and ventral axons in tectum, experiments in which axons grow from ectopic positions towards their proper target site in tectum (Harris, 1984, 1986) suggest that absence of axonal preordering does not prohibit their termination at appropriate target sites. In this context the behavior of occasional misrouted axons is also instructive. Axons that had entered in the inappropriate dorsal or ventral hemitectum were seen in our preparations to cross over the tectal equator to grow towards their target. This behavior is similar to misrouted axons in the regenerating retinotectal projection in goldfish (Stuermer, 1988a, b). It suggests that not only the pathways but also the tectum must possess positional information that is recognized by the growing axons.

Evidence for the existence of spatial markers associated with tectal cell surfaces was provided by in vitro culture systems (Walter et al., 1987a). When given a choice between membranes derived from rostral and caudal tectum, embryonic chick retinal axons grow selectively on membranes of their natural target. This preference of temporal axons for rostral tectal membranes has recently also been shown for regenerating goldfish retinal axons (Stuermer and Vielmetter, 1987a; Stuermer, 1988c), suggesting that the same mechanisms of map making are acting in these species. Recent evidence from these in vitro studies indicates that the restriction of temporal axons to rostral membranes is due to an inhibitory influence on these axons, mediated by contact with caudal membranes (Walter et al., 1987b). Nasal axons are insensitive to the "caudal inhibition." In the light of these findings, one could speculate that this inhibitory influence might prevent temporal axons in the zebrafish embryo from invading into caudal tectum, even when the nasal axons are absent.

If temporal axons are repulsed from caudal tectum in the fish embryo, they should decelerate when they come under the influence of the inhibitor, or their growth cones should retract after encounters with the inhibitor-providing cells (Kapfhammer and Raper, 1987). Observations of growing axons in the living zebrafish will help to solve this question. However, an inhibitory influence on temporal axons by caudal tectum does not suffice for the alignment of the map. Instead, one has to postulate an attractant for nasal axons associated with caudal tectum since they grow into caudal tectum with or without the presence of temporal axons in rostral tectum (Humphrey and Stuermer, 1987; Meyer, 1987).

\section{Comparison with related findings}

In the Xenopus embryo, dorsal and ventral axons were reported to occupy retinotopic sites in tectum at stage $39 / 40$, that is, at the beginning of the tectal innervation (Holt and Harris, 1983). Flectrophysiological recordings suggest that the axons are also retinotopically aligned in the rostrocaudal axis of tectum at stage 40 (Holt and Harris, 1983). Slightly contradictory to this result are anatomical findings by O'Rourke and Fraser (1986) showing that the nasal and temporal axons are coextensive over the rostrocaudal tectal axis up to stage 47 . They are reported to segregate by a mechanism involving a retraction of temporal 
axons and an advancement of nasal axons into newly created caudal tectum (O'Rourke and Fraser, 1986). Our results also showed an initial overlap of the temporal and nasal axons but only in the rostral tectum. Invasion of temporal axons into caudal tectum and retraction from these regions have not been observed in zebrafish.

Using intracellular injections of cobalt, Sakaguchi and Murphey (1985) revealed the extent of the embryonic arbors, the largest of which cover $75 \%$ of the tectal length and $35 \%$ of its width. In zebrafish we found the largest arbors to cover not more than 40 and $20 \%$ of axes of the tectal core region. This suggests that the initial map in zebrafish may be more precise than that in Xenopus. Common to both Xenopus (Sakaguchi and Murphey, 1985) and zebrafish is the fact that arbors in the embryo are smaller than in the adult. However, since the embryonic tecta are small, the tectal coverage of these embryonic arbors is substantially larger than in the adult. In zebrafish, the mean of the tectal coverage of the arbors in the embryos is $2.8 \%$, and in the adult, $0.37 \%$. Thus, the evolution of the adult map seems to imply an enlargement of the axonal arbors concurrent with a more rapid and more substantial increase in tectal area. In contrast to the case in Xenopus and fish (Gaze et al., 1974; Raymond and Easter, 1983), the chick tectum reaches its final size during early stages of embryogenesis, and no further growth in postembryonic stages takes place (DeLong and Coulombre, 1965; Crossland et al., 1974). In chick, the first axons derived from central retina grow into the central portion of the tectum at embryonic day (E) 9 and form arborizations of mature dimensions at E13-14 within this region (Thanos and Bonhoeffer, 1987). In contrast, the initial arbors in the rodent tectum possess widespread branches (Schneider et al., 1981), and they concentrate into dense restricted arbors in the adult, so that these arbors mature by pruning (Schneider et al., 1981).

It is unlikely that arbors seen in the adult zebrafish are purely a result of an elongation of the embryonic branches and an addition of new branches. Instead, retraction of certain branchcs and formation of new ones at other sites of the axon are probably involved in arbor maturation as well (Fujisawa, 1987). In fact, no other mechanism can account for the shift of the arbors during the ongoing growth of the eye and tectum (Easter and Stuermer, 1984; Stuermer, 1984; Stuermer and Easter, 1984a; Fujisawa, 1987). In normal fish embryos, however, arbors do not appear to be as widespread as in rodents (Schneider et al., 1981) or as in fish during optic nerve regeneration (Schmidt, 1985; Stuermer, $1988 \mathrm{a}, \mathrm{b})$.

Since the vast majority of embryonic retinal axons grow in direct routes towards their target, their path is very different from that in regenerates, which travel in very abnormal routes (Cook, 1983; Stuermerand Easter, 1984a; Stuermer, 1986, 1988a, b). Since regenerating axons have their growing endings or large arborizations transiently at ectopic tectal regions (Stuermer, $1988 \mathrm{a}, \mathrm{b}$ ), the initial map in regencrates is diffuse (Meyer et 1985; Rankin and Cook, 1986). In contrast to findings in the regenerate (Schmidt, 1985), our results are consistent with those gained from Xenopus embryos (Holt and Harris, 1983) showing that the embryonic map is precise and not diffuse. This does not mean that the formation of the retinotopic axon arbor order in tectum of regenerates and embryos is controlled principally by different mechanisms. Evidence by others and ourselves indicate that the regenerating axons at any ectopic site are able to achieve target-directed routes (Fujisawa et al., 1982; Stuermer, $1988 \mathrm{a}, \mathrm{b})$. These findings indicate that homefinding of regen- erating axons is also under the influence of spatial markers on tectum (Gierer, 1987).

In conclusion, it appears that preordering of axons in the pathway facilitates the formation of the retinotopic map, but map formation is not prevented, but only slowed, when the path of axons is disorganized.

\section{References}

Attardi, D. G., and R. W. Sperry (1963) Preferential selection of central pathways by regenerating optic fibers. Exp. Neurol. 7: 46-64.

Bodick, N., and C. Levinthal (1980) Growing optic nerve fibers follow neighbors during embryogenesis. Proc. Natl. Acad. Sci. USA 77:43744378.

Bonhocffcr, F., and A. Gicrer (1984) How do retinal axons find their targets on tectum? TINS 7: 378-381.

Cook, J. E. (1983) Tectal paths of regenerating optic axons in the goldfish: Evidence from retrograde labelling with horseradish peroxidase. Exp. Brain Res. 51: 433-442.

Cook, J. E., and J. T. Horder (1977) The multiple factors determining retinotopic order in the growth of optic fibres into the optic tectum. Phil. Trans. R. Soc. London [Biol.] 278: 261-276.

Cook, J. E., and E. C. C. Rankin (1986) Impaired refinement of the regenerated retinotectal projection of the goldfish in stroboscopic light: A quantitative study. Exp. Brain Res. 63: 421-430.

Crossland, W. J., W. M. Cowan, L. A. Rogers, and J. P. Kelly (1974) Specification of the retino-tectal projection in the chick. J. Comp. Neurol. 155: 127-164.

DeLong, G. R., and A. J. Coulombre (1965) Development of the retinotectal projection in the chick embryo. Exp. Neurol. 13: 351363.

Easter, S. S., and C. A. O. Stuermer (1984) An evaluation of the hypothesis of shifting terminals in goldfish optic tectum. J. Neurosci. 4: 1053-1063.

Fawcett, J. W., and R. M. Gaze (1982) The retinotectal fibre pathways from normal and compound eyes in Xenopus. J. Embryol. Exp. Morphol. 72: 19-32.

Fraser, S. E. (1980) A differential adhesion approach to the patterning of nerve connections. Dev. Biol. 79: 453-464.

Fujisawa, H. (1987) Mode of growth of retinal axons within the tectum of Xenopus tadpoles, and implications in the ordered neuronal connection between the retina and tectum. J. Comp. Neurol. 260: 127139.

Fujisawa, H., N. Tani, K. Watanabe, and Y. Ibata (1982) Branching of regenerating retinal axons and preferential selection of appropriate branches for specific neuronal connection in the newt. Dev. Biol. 90: 43-57.

Gaze, R. M. (1970) The Formation of Nerve Connections, Academic, London.

Gaze, R. M., M. J. Keating, and S. H. Chung (1974) The evolution of the retinotectal map during development in Xenopus. Proc. R. Soc. London [Biol.] 185: 301-330.

Gierer, A. (1987) Directional cues for growing axons forming the retinotectal projection. Development 101: 479-489.

Harris, W. A. (1984) Axonal pathfinding in the absence of normal pathways and impulse activity. J. Neurosci. 4: 1153-1162.

Harris, W. A. (1986) Homing behavior of axons in the embryonic vertebrate brain. Nature 320: 266-269.

Harris, W. A., C. E. Holt, T. A. Smith, and N. Gallenson (1985) Growth cones of developing retinal cells in vivo, on culture surfaces, and in collagen matrices. J. Neurosci. Res. 13: 101-123.

Harris, W. A., E. C. Holt, and F. Bonhoeffer (1987) Retinal axons with and without their somata, growing to and arborizing in the tectum of Xenopus embryos: A time lapse video study of single fibers in vivo. Development 101: 123-133.

Holt, C. E., and W. A. Harris (1983) Order in the initial retinotectal map in Xenopus: A new technique for labelling growing nerve fibres. Nature 301: 150-152.

Honig, M. G., and R. J. Hume (1986) Fluorescent carbocyanine dyes allow living neurons of identified origin to be studied in long-term cultures. J. Cell. Biol. 103: 171-187.

Humphrey, M. F., and C. A. O. Stuermer (1987) Tectal pathways of regenerating goldfish optic axons after half-nasal or half-temporal retinal removal. Development 102: 479-499.

Jacobson, M., and R. M. Gaze (1965) Selection of appropriate ter- 
minations by regenerating optic fibres in the adult goldfish. Exp. Neurol. $13: 418-430$.

Kandel, E. R., and J. H. Schwartz (1985) Principles of Neural Science, Elsevier, New York.

Kapfhammer, J. P., and J. A. Raper (1987) Interactions between growth cones and neurites growing from different neural tissues in culture. $\mathbf{J}$. Neurosci. 7: 1595-1600.

Meyer, R. L. (1987) Tests for relabelling the goldfish tectum by optic fibers. Dev. Brain Res. 31: 312-318.

Meyer, R. L., and R. W. Sperry (1976) Retinotectal specificity: Chemoaffinity theory studies on the development of behavior and the nervous system. In Neural and Behavioral Specificity, G. Gottlieb, ed., pp. 111-145, Academic, New York.

Meyer, R. L., K. Sakurai, and E. Schauwecker (1985) Topography of regenerating optic fibers in goldfish traced with local wheat germ injections into retina: Evidence for discontinuous microtopography in the retinotectal projection. J. Comp. Neurol. 239: 27-43.

O'Rourke, N. A., and S. E. Fraser (1986) Dynamic aspects of retinotectal map formation revealed by a vital-dye fiber-tracing technique. Dev. Biol. 114: 265-276.

Purves, D., and J. W. Lichtman (1985) Principles of Neural Development, Sinauer, Sunderland, MA.

Rager, G., and B. von Oeynhausen (1979) Ingrowth and ramification of retinal fibers in the developing optic tectum of the chick embryo. Exp. Brain Res. 33: 65-78.

Rankin, E. C. C., and J. E. Cook (1986) Topographic refinement of the regenerating retinotectal projection of the goldfish in standard laboratory conditions. A quantitative WGA-HRP study. Exp. Brain Res. 63: 409-420.

Raymond, P., and S. S. Easter (1983) Postembryonic growth of the optic tectum in goldfish. J. Neurosci. 3: 1077-1091.

Sakaguchi, D. S., and R. K. Murphey (1985) Map formation in the developing Xenopus retinotectal system: An examination of ganglion cell terminal arborizations. J. Neurosci. 5: 3228-3245.

Schmidt, J. T. (1978) Retinal fihers alter tectal positional markers during the expansion of the half retinal projection in goldfish. J. Comp. Neurol. 177: 279-300.

Schmidt, J. T. (1985) Formation of retinotopic connections: Selective stabilization by an activity-dependent mechanism. Cell. Mol. Neurobiol. 5: 65-84.

Schmidt, J. T., and D. L. Edwards (1983) Activity sharpens the map during the regeneration of the retinotectal projection in goldfish. Brain Res. 269: 29-39.

Schneider, G. E., L. Rava, G. M. Sachs, and S. Jhaveri (1981) Widespread branching of retinotectal axons: Transient in normal development and anomalous in adults with neonatal lesions. Soc. Neurosci. Abstr. 7: 732.
Schwartz, M., and B. W. Agranoff (1981) Outgrowth and maintenance of neurites from cultured goldfish retinal ganglion cells. Brain Res. 206: 331-343.

Sperry, R. W. (1963) Chemoaffinity in the orderly growth of nerve fiber patterns and connections. Proc. Natl. Acad. Sci. USA 50:703709.

Stuermer, C. A. O. (1984) Rules for retinotectal terminal arborizations in the goldfish optic tectum. A wholemount study. J. Comp. Neurol. 229: 214-232.

Stuermer, C. A. O. (1986) Pathways of regenerated retinotectal axons in goldfish. I. Optic nerve, tract and tectal fascicle layer. J. Embryol. Exp. Morphol. 93: 1-28.

Stuermer, C. A. O. (1988a) The trajectories of regenerating retinal axons in the goldfish. I. A comparison of normal and regenerated axons at late regeneration stages. J. Comp. Neurol. 267: 55-68.

Stuermer, C. A. O. (1988b) The trajectories of regenerating retinal axons in the goldfish tectum. II. Exploratory branches and growth cones on axons at early regeneration stages. J. Comp. Neurol. 267: $69-91$.

Stuermer, C. A. O. (1988c) Path- and homefinding of regenerating retinal axons in goldfish. In Post-lesion Neural Plasticity. H. Flohr, ed., Springer, Berlin (in press).

Stuermer, C. A. O., and S. S. Easter (1984a) A comparison of the normal and regenerated retinotectal pathways of goldfish. J. Comp. Neurol. 223: 57-76.

Stuermer, C. A. O., and S. S. Easter (1984b) Rules of order in the retinotectal fascicles of goldfish. J. Neurosci. 4: 1045-1051.

Stuermer, C. A. O., and J. Vielmetter (1987a) Path- and homefinding of regenerating retinal axons in goldfish. 13. EMBO Symposium, Heidelberg.

Stuermer, C. A. O., and J. Vielmetter (1987b) Embryonic development of the retinotectal projection in zebrafish. Soc. Neurosci. Abstr. 13: 1689.

Thanos, S., and F. Bonhoeffer (1987) Axonal arborization in the developing chick retinotectal system. J. Comp. Neurol. 261: 155-164.

Walter, J., S. Henke-Fahle, and F. Bonhoeffer (1987a) Avoidance of posterior tectal membranes by temporal retinal axons. Development 101: 909-913.

Walter, J., B. Kern-Veits, J. Huf, B. Stolze, and F. Bonhoeffer (1987b) Recognition of position-specific properties of tectal cell membranes by retinal axons in vitro. Development 101: 685-696.

Willshaw, D. J., and C. von der Malsburg (1976) How patterned neural connections can be set up by self-organization. Proc. R. Soc. London [Biol.] 194: 431-445. 